\title{
ESTIMATING EXCHANGE RATE EXPOSURES: SOME "WEIGHTY” ISSUES
}

\author{
Gordon M. Bodnar \\ M.H. Franco Wong \\ Working Paper 7497 \\ http://www.nber.org/papers/w7497
NATIONAL BUREAU OF ECONOMIC RESEARCH 1050 Massachusetts Avenue
Cambridge, MA 02138
January 2000

The authors gratefully acknowledge financial support from the Weiss Center for International Financial Research at the Wharton School and the Center for Financial Reporting and Management at the Haas School of Business. The authors also thank seminar participants at DePaul University, Harvard Business School, the University of Illinois, University of Minnesota, the 1999 International Finance Conference (Georgia Tech), and the $4^{\text {th }}$ Annual Washington Area Finance Association Conference for their helpful comments and suggestions. The views expressed herein are those of the author and not necessarily those of the National Bureau of Economic Research.

(C) 2000 by Gordon M. Bodnar and M.H. Franco Wong. All rights reserved. Short sections of text, not to exceed two paragraphs, may be quoted without explicit permission provided that full credit, including $\mathbb{C}$ notice, is given to the source. 
Estimating Exchange Rate Exposures: Some "Weighty" Issues

Gordon M. Bodnar and M.H. Franco Wong

NBER Working Paper No. 7497

January 2000

JEL No. F3

\section{$\underline{\text { ABSTRACT }}$}

From a sample of 910 U.S. firms over the period 1977 - 1996, we find that structure of the empirical model has significant impacts on resulting estimates of exchange rate exposures from equity returns. While lengthening the return horizon has minimal impact on exposure estimates, the inclusion of a market portfolio in the specification results in significant changes to the exposure estimates. We further demonstrate that different definitions of the market portfolio result in important differences in the overall distribution of exposure estimates and the interpretations of the sign, size, and significance of many firms' exposures. The source of the exposure differences across market portfolios is due to a strong size-exposure relation for U.S. firms. Surprisingly, this sizeexposure relation does not appear to be driven by an underlying correlation between size and foreign cash flow position of the firms. An alternative model specification using matched CRSP capital-based size portfolios as controls for market movements in the exposure model produces firm-level exposures with a stronger relation to foreign cash flows and less of a correlation with firm size.

Gordon M. Bodnar

Paul H. Nitze School of Advanced International Studies, The Johns Hopkins University

1740 Massachusetts Ave NW

Washington DC 20036

and NBER

bodnar@jhu.edu
M.H. Franco Wong

Haas School of Business

University of California at Berkeley

Berkeley, CA 94720-1900

fwong@haas.berkeley.edu 


\section{Introduction}

For the past decade, researchers have been empirically investigating the exchange rate exposure of firms. Following Adler and Dumas (1984), most of this research measures the exposure as the elasticity between changes in firm value and an exchange rate. Empirically, this exposure elasticity is obtained from a regression of stock returns on an exchange rate change, often with additional control variables such as a market portfolio return. Although estimates of exposure for individual firms, as well as industry portfolios, have tended to suffer from low levels of statistical significance, tests have demonstrated sensible patterns of cross sectional variation. The exposure estimates vary across firms in a manner broadly consistent with the theoretical predictions of the impact of exchange rate changes on firms' cash flows and resulting market value (see e.g., Jorion (1990) and Bodnar and Gentry (1993)).

Despite this success in explaining the cross-section variation in exposures, the difficulty in identifying statistically significant and economically meaningful point estimates of a firm's exposure has cast doubts on the usefulness of these market-based estimates of exchange rate exposure. Users of exchange rate exposure estimates, either investors looking to hedge their portfolios or corporate managers looking to make corporate risk management decisions, are understandably put off by the lack of statistically significance and economic meaning in these estimates. Moreover, from an academic perspective, it draws into question the basic premise of how significantly and in what fashion exchange rate movements impact firm performance and value.

The early exposure studies and many of the more recent detailed empirical studies on exchange rate exposure of U.S. firms (e.g., Allayannis (1995) (1996), Williamson (1998), Allayannis and Ofek (1998), Wong (1999)) all share several common methodological characteristics in their specifications. First, they include a market portfolio in the exposure regression to assist exchange rate changes explaining total stock return variance. Second, in keeping with the standard practice in the asset pricing literature, these studies use monthly return horizon to obtain exposure estimates.

In the original approach to estimating exchange rate exposures, as suggested by Adler and Dumas (1984), there was no role for a market portfolio nor was there any discussion of the particular horizon over which returns should be measured. However, as is clear from simple econometrics, the inclusion of a market portfolio return in an exposure specification will shift the distributions and change the statistical properties of the exposure estimates. Moreover, if market participants do not instantaneously reflect the impact of exchange rate changes in firm value, 
differences in the return horizon of returns will influence the size and significance of the exposure elasticity estimates. Together, these two issues suggest that the sign, magnitude, and significance of a firm's estimated exchange rate exposure are only meaningful with reference to a particular empirical model specification. This raises the question of what is the "right" empirical specification when making statements about the impact of an exchange rate change on a firm's financial performance and value. Surprisingly little research has been done on the sensitivity of the exposure elasticity estimates to these particular specifications of the empirical model.

The purpose of this paper is to investigate the importance of model structure on the empirical estimation of exchange rate exposure using a large sample of U.S. firms over the period 1977 - 1996. In particular, we examine how equity exposure estimates are influenced by model specification issues such as the practice of controlling for a market return and using a standard monthly return horizon. The analysis is done within the structure of a linear regression model in which we use return horizons ranging from one month to 60 months. We use overlapping observations regression techniques to allow for full use of the data in longer horizon regressions.

The original Adler and Dumas approach to estimating exposures involves measuring the elasticity of a firm's stock returns with an exchange rate change using a univariate regression. Although easy to implement, we demonstrate that these estimates of exposure (hereafter, "total" exposures) possess several features that have puzzled researchers. First, when estimated over the standard one-month return horizon, the percentage of statistically significant total exposure estimates are generally lower than expected given most researchers' priors (generally less than 20 percent of the firms have exposure elasticities that are significant at the 10 percent level). Second, the cross sectional distribution of total exposure elasticities tends to suggest that the average firm's value increases with an appreciation of the U.S. dollar, and that of firms significantly affected by exchange rates, far more benefit than are harmed by a dollar appreciation. This result is at odds with the previous research that demonstrates that the annual profits of U.S. firms are positively related to dollar depreciations (see, e.g., Clarida (1992), Hung (1992), Uctum (1996)). Since profits are a close proxy for cash flows that should related directly to firm value, the divergence of these results is puzzling.

As our first step, we examine whether these features of the total exposure estimates persist when the return horizon is lengthened. Upon extending the return horizon from three months to sixty months, we continue to find puzzling results for the total exposure estimates. The percentage of statistically (positively or negatively) significant total exposure estimates remains low (except for very long horizons). Also troubling, over the full period the 
distribution of the total exposure estimates shifts back and forth from positive to negative as the return horizon increases. The most disturbing feature of these total exposures is that the cross sectional distributions of total exposure estimates at all return horizons, display economically significant variation across subperiods. These shifts in the distribution of total exposure elasticities over subperiods appear too large and too sudden to be explainable by structural changes in the firm's cash flow sensitivities or market structures.

These features of the total exposures arise from the fact that they capture the entire correlation between changes in firm value and the changes in exchange rate. In addition to cash flow effects, the total exposures also contain the influence of other value-relevant factors, including common "macroeconomic" factors, which happen to be correlated with exchange rate changes over the estimation period. If the correlations of these value-relevant factors with the exchange rate are large, they can dramatically shift the distribution of "total" exposure away from that predicted by cash flow models. Moreover, if these correlations are spurious, they can result in significant instability of exposures estimated over shorter sample periods.

Fortunately, most empirical research on exchange rate exposures of U.S. firms has not estimated total exposure elasticities. Functionally, to deal with the very low explanatory power of the exchange rate for stock returns, it is common practice for most researchers to include a market portfolio return variable on the right-hand side of the regression model. The common market portfolio is a value-weighted portfolio. We document that this modification of the model works to reduce some of the puzzling features of the total exposure estimates. First and most importantly, the inclusion of the market portfolio return variable implicitly controls for value-relevant marketwide factors - "macroeconomic" effects - that are correlated with the exchange rate over the estimation period. This makes the resultant conditional exposure estimates (hereafter, "residual" exposure) more stable across horizons and subperiods. Second, because the market return explains a substantial amount of the typical firm's stock return variation, its inclusion reduces the residual variance of the regression, thereby improving the precision of the residual exposure estimates. Consequently, the percentage of firms with statistically significant residual exposure estimates increases, albeit slightly.

However, these residual exposures elasticity estimates also have a peculiar feature that their distribution has a positive shift relative to the total exposure estimates. This implies that upon controlling for the common value effects correlated with exchange rates, the typical firm experiences an increase in value from a dollar appreciation. 
Such a result deepens the contradiction between the measured impact of exchange rates on profits and the measured impact of exchange rates on firm value.

The shift in the exposures is explained by recognizing that the "residual" exposure estimates measure the deviation of the firm's exposure from the market portfolio's exposure. If the market portfolio itself has a non-zero exposure, it will shift the distribution of the residual exposure estimates. The observed positive shift in the residual exposures relative to the total exposures indicates that the VW market portfolio has a less positive exposure than the average firm. This is consistent with the fact that the VW market is dominated by large firms that are more likely to be multinational and/or export oriented and likely to experience more negative cash flow reactions to dollar appreciations than other US firms. Thus controlling for the VW market not only removes the "macroeconomic" effects from the exposure estimates, but also a more negative cash flow effects of the larger firms. This confounds the interpretation of the resulting exposure estimates levels as a measure of the cash flow impact of exchange rate changes predicted by corporate finance models. This is a problem for exposure studies attempting to make statements about the absolute level of firms' cash flow exposures.

An approach to reduce the distortion in the residual exposure estimates would be to control for the "macroeconomic" influences in the exposures estimates using an equal-weighted (EW) market portfolio. While removing the market-wide impacts on the exposure estimates, it removes only the equally weighted average impact of the exchange rate on firm cash flows. Since most studies of exchange rate exposures give equal weighting to the exposure estimates when computing summary statistics, this equal weighted control variable should lead to less distortion in the residual exposures. We demonstrate that this is the case. Replacing the VW market portfolio with the EW market portfolio in the empirical model leads to substantial differences in the distribution of residual exposure elasticities. While maintaining the benefits of improved statistical significant and temporal stability from controlling for the market-wide influences, the cross sectional means and medians of the residual exposures are now generally all negative. Thus, the residual exposure estimates conditional on the EW market portfolio appear more interpretable as cash flow effects as they are now more consistent with the exposure results on corporate profits.

As we mentioned above, this change in exposures arises because the U.S. VW and EW market portfolios have economically different correlations with the exchange rate. We further demonstrate that this is due to a strong relation between firm size and the sign of the exchange rate exposure. Large (market capitalization) firms are more likely to gain from a depreciation of the U.S. dollar and small firms more likely to gain from an appreciation of the 
dollar. While this might simply be due to a natural correlation between foreign cash flow position and firm size, we find that firm size, rather than cash flow sensitivity, mostly drives this relation. In particular, when we examine size portfolios that are broken down by degree of international activity, we find that large firms with no foreign operations actually exhibit exposures that are more negative than small firms with extensive foreign operations. This size-exposure relation indicates a potential problem for studies examining cross sectional differences in exposures across firms (e.g., Jorion (1990), Allayannis and Ofek (1998) and Wong (1999)). Specifically, a failure to control for size in the cross sectional regression causes a correlated omitted variable problem, which will misstate the significance of other variables in the regression. Because of this size-exposure relation, we consider an alternative approach to estimate firm-specific exposures. Instead of using a market portfolio to control for "macroeconomic" effects, we suggest using a size-matched (market capitalization based) portfolio. We demonstrate this approach using the CRSP capital-based decile portfolios as market control. We find that the resulting exposures are not only less related to firm size than the common residual exposures using the market portfolio, but also that they are generally negative. The latter property is appealing because it is consistent with what one would expect for the estimates to be interpreted as a measure of exchange rate related cash flow impact.

The rest of the paper is organized as follows. Section II discusses the role of exposure estimates and examines the methodological issues facing the researcher in the estimation of exchange rate exposure. Section III describes the data and research design. Section IV presents results of the impacts of these methodological choices on the estimates of exposure and demonstrates the resulting relation between standard exposure estimates and firm size. Section V proposed an alternative approach to estimate exposures to reduce the exposure- size relation. Section VI summarizes and discusses the implication of the paper's findings for exchange rate exposure research.

\section{Exchange Rate Exposure}

\section{A. Measurement of Exchange Rate Exposure}

The estimation of exchange rate exposure is a relatively new area in international finance. ${ }^{1}$ In response to the onset of fluctuating exchange rates in 1973, managers became concerned about the impact of exchange rate fluctuations on firms. The early papers discussing exchange rate exposures (e.g., Shapiro (1974), Hodder (1982), Levi (1983), Hekman (1985), and Flood and Lessard (1986)) examine the impact of the exchange rate on the firms

\footnotetext{
${ }^{1}$ See Stulz and Williamson (1997) for a discussion of the various ways in which exchange rate exposure can be measured.
} 
by modeling its impact on the firms' cash flows. From this work came the predictions that the cash flow sensitivity of a firm to the exchange rate should depend on the nature of the firm's activities, such as the extent to which it exports and imports, its involvement in foreign operations, the currency denomination of its competition, and the competitiveness of its input and output markets. ${ }^{2}$ Most theoretical models of exchange rate exposures, such as Marston (1998), suggest that the firm's exchange rate exposure is a function of its net foreign currency revenues. ${ }^{3}$

This theoretical examination of exposure coincides with the interest of firm managers in understanding how their firm's cash flows will be affected by exchange rate change in order to make value-maximizing risk management decisions. For risk management purposes, the focus of the exchange rate fluctuations on the firm's cash flows is supported by the theoretical arguments motivating corporate risk management. Most of the theoretical justifications for a firm managing its currency risk come directly from cash flow volatility arguments (see, e.g., Smith and Stulz (1985), Stulz (1984), Froot, Sharfstein, and Stein (1993)). Thus, for purposes of making optimal risk management decisions, managers were interested in an exposure measure that gauged their firm's cash flow sensitivity to exchange rate changes. ${ }^{4}$

This suggests an approach of measuring exchange rate exposure by modeling the actual cash flows of the firm. Such an approach is typified by the approach of the pharmaceutical firm, Merck, in which a model of the firm's foreign currency cash flows is built (Lewent and Kearney (1990)). From this model the impact of various exchange rate changes on the operating decisions and financial performance of the firm can be estimated and optimal hedging decisions made. Such an approach, however, suffers from the difficulty of incorporating all of the complexities of the cash flow effects into the model, such as competitive reactions and impacts of market parameters and structure. For example, Marston (1998) demonstrates the complexity of determining the demand and cost derivatives necessary for estimating the exact exposure for the simple case of a Cournot duopoly with constant elasticity demand functions. Such approaches require significant amounts of firm-specific and competitor-specific information that are available, if at all, to those inside the firm. Consequently, this cash flow modeling approach for determining exposure, while useful in identifying the determinants of exposure, is good only for specific situations

\footnotetext{
${ }^{2}$ Of course, the exposure of the firms will also depend upon the extent to which it offsets the remaining risk from these activities through financial hedging.

${ }^{3}$ For example, Marston (1998) demonstrates that the exposure of an exporting monopolist is exactly its net foreign currency revenues. Even under other competition structures, the exposure is generally proportional to the net foreign currency revenue position.

${ }^{4}$ Such a view is consistent with the results of survey data (e.g., Bodnar and Marston, 1996), which overwhelmingly suggest that managers' primary goal of hedging is to reduce volatility in cash flows, with the goal of reducing volatility in firm value as much less important.
} 
and not easily applicable to multi-firm studies or large-scale cross-firm comparisons of exchange rate exposures. For these sorts of studies, another approach to measuring exchange rate exposures using easily accessible information is needed.

An alternative to this cash flow modeling approach is the approach suggested by Adler and Dumas (1984). Rather than focus on the difficult to observe cash flows, they focus on the readily observable market value of the firm. Their approach utilized the fact that the present value of the firm's future cash flows is the market value of the firm. Under this assumption, they show that the exposure could be determined from the elasticity of firm value with respect to the exchange rate, which in turn could be obtained from a simple regression of a firm's stock returns on an exchange rate change variable. This approach, which only requires the researcher to obtain market data, greatly simplifies the estimation of exchange rate exposures and gives rise to the possibility of large-scale empirical studies on exchange rate exposure.

\section{B. Methodological Issues in the Measurement of Exchange Rate Exposure}

\section{B.1. The Specification of the Empirical Model}

The insight of Adler and Dumas (1984) is in defining the exposure elasticity as the change in the market value of the firm resulting from a unit change in the exchange rate. While this is the exact definition of exposure that an investor is interested in, if the change in the value of a firm is directly related to the change in a firm's expected cash flows, this definition of exposure will also be the measure that the risk manager of the firm would be interested in.

The beauty of their approach is that the exposure elasticity of the firm can be obtained from the coefficient on the exchange rate variable in the following regression

$$
R_{j}=\alpha_{j}+\delta_{j} X R+\varepsilon_{j}
$$

where $R_{j}$ is the stock return for firm $j, X R$ is the percentage change in an exchange rate variable, defined as the home currency price of foreign currency $(\mathrm{HC} / \mathrm{FC})$, and $\delta_{j}$ is the elasticity of firm value to the exchange rate change. This elasticity indicates the firm's average exposure over the estimation period, in home currency units, as a percentage 
of the firm's market value. ${ }^{5}$ As they pointed out, this definition of exchange rate exposure is simply a variance decomposition of a firm's returns into a component that was correlated with the exchange rate change and a component that was orthogonal to exchange rate changes. We will refer to $\delta_{j}$ as the total exposure elasticity of firm j.

The total exposure of a firm will consist of two parts. The first is an estimate of the average value effect of the present value of cash flow changes caused by exchange rate movements. This is the effect that is predicted by corporate finance / industrial organization models of exposure. The second part is non-exchange rate related phenomenon that affect either cash flows or valuations and are spuriously correlated with the exchange rate variable. While a portion of this latter part will be idiosyncratic effects that cannot be controlled for directly, a portion of this effect will include "macroeconomic" effects that influence the valuation of all firms, such as changes in the risk free rate or the market risk premium, or other non financial factors such as investor sentiment. If these value-relevant influences are to any degree correlated with the exchange rate over the estimation period, they will influence the estimate of "total" exposure and make it difficult to interpret the estimated "total" exposure in terms of the cash flow and industrial organization models of exposure. ${ }^{6}$

If the correlation of this "macroeconomic" effect with exchange rates could be modeled, it would be possible to adjust the total exposure estimates to remove this impact. However, previous research has not been able to identify a consistent relation between observed proxies such as interest rates or market risk premiums for these “macroeconomic" impacts on firm value.

Instead, to control for the common "macroeconomic" influences on "total" exposure elasticities, most empirical studies include the return to a market portfolio along with the exchange rate variable in their empirical model. The market portfolio return not only controls for "macroeconomic" influences, but also dramatically increases the proportion of the total stock return variation explained for a given firm over equation (1). By reducing the residual variance of the model, the market portfolio return also improves the precision of the exposure estimates, which has been a serious concern to prior researchers. Thus, this commonly estimated exposure model looks like

\footnotetext{
${ }^{5}$ In mathematical terms, the exposure of the firm as defined by Adler and Dumas (1984) is the derivative of firm value with respect to the exchange rate, $\mathrm{dV} / \mathrm{dS}$. The regression coefficient, as an elasticity then becomes $\mathrm{dV} / \mathrm{dS}(\mathrm{S} / \mathrm{V})$. To obtain the actual exposure, the elasticity estimate from the regression must be multiplied by $\mathrm{V}$ and converted into foreign currency by dividing by $\mathrm{S}$.

${ }^{6}$ This problem does not affect cross sectional evaluation of the exposure estimates as the effect is common to all firms and fall out when considering the relative exposures as opposed to the absolute exposure.
} 


$$
R_{j}=\alpha_{j}+\gamma_{j} X R+\beta_{j} R_{M}+\varepsilon_{j}
$$

where $R_{M}$ is the return on a market portfolio, $\beta_{j}$ is the beta of the firm with respect to the market portfolio and $\gamma_{j}$ is the exchange rate exposure elasticity of firm $j$ from this modified regression. Equation (2) is generally preferred by researchers (e.g., Jorion, 1990, Bodnar and Gentry (1993), Allayannis (1995), and Wong (1999)) as it explains significantly more of the total variation in firms return than equation (1) and it can be motivated as an extension of the familiar market model.

It is important to note, and often overlooked in the empirical literature, that the definition of the exposure coefficient from equation (2) is now different. This modified exposure coefficient $\gamma_{j}$ actually measures the exchange rate exposure elasticity of the firm as the residual difference between the firm's total exposure elasticity and the market's exposure elasticity adjusted by the firm's market beta. ${ }^{8}$ Therefore, we will refer to $\gamma_{j}$ as the residual exposure elasticity of the firm.

It should be noticed that the incorporation of the market return in the model controls for the market portfolio's own exchange rate exposure. The estimated "residual" exposure elasticity will differ from the "total" exposure elasticity whenever the market portfolio has a non-zero exposure to the exchange rate (or the firm has a non-zero market beta). When the market portfolio's exposure is non-zero, the distribution of "residual" exposure elasticities will be shifted relative to the "total" exposure elasticities. Because of this, the interpretation of having "zero" exposure will not mean the same thing across these two measures if the market has a non-zero exposure. This is important as the empirical result of having "zero" exposure is often given the economic meaning in analysis

\footnotetext{
${ }^{7}$ Most studies trying to consistently link exchange rate changes with other macro-economic variables have limited success. This is consistent with the common view that exchange rates evolve as random walks. There is a literature investigating pricing of exchange rate risk. This literature suggests that any risk premium of exchange rates is significantly time varying and difficult to predict.

${ }^{8}$ This can be shown as follows. Using matrix notation where $\boldsymbol{F}$ is a $T$ by 2 matrix of the constant term and the exchange rate change variable and $\boldsymbol{R}_{j}$ is an $T$ by 1 vector of stock returns for firm $j$, the statistical definition of the coefficients from equation (1) is
}

$$
\boldsymbol{\delta}_{j}=\left(\boldsymbol{F} \boldsymbol{F}^{-1} \boldsymbol{F} \boldsymbol{R}_{j},\right.
$$

where $\boldsymbol{\delta}_{j}$ is the vector coefficient estimates of the intercept term $\left(\alpha_{j}\right)$ and the total exchange rate exposure elasticity $\left(\delta_{j}\right)$. With the inclusion of the market return as a $T$ by 1 vector, $\boldsymbol{M}$, in equation (2), the statistical definition of the exposure coefficient (including the constant term) is

$$
\boldsymbol{\gamma}_{j}=\left(\boldsymbol{F}^{`} \boldsymbol{F}\right)^{-1} \boldsymbol{F}^{\top} \boldsymbol{R}_{j}-\left(\boldsymbol{F} \boldsymbol{F}^{-1} \boldsymbol{F}^{\top} \boldsymbol{M} \beta_{j}\right.
$$

See partitioned regression in Greene (1990), among others. The first term of $\boldsymbol{\gamma}_{\boldsymbol{j}}$ is the same as the $\boldsymbol{\delta}_{\boldsymbol{j}}$ from (E1) above but this is reduced by the second term. Since the term $(\boldsymbol{F} \boldsymbol{F})^{-1} \boldsymbol{F}^{\prime} \boldsymbol{M}$ is simply the coefficients from the regression of the market return on a constant and the exchange rate change (i.e., the exchange rate exposure elasticity of the market portfolio), if we define these coefficients as $\boldsymbol{\delta}_{M}$ we can rewrite (E2) as

$$
\boldsymbol{\gamma}_{j}=\boldsymbol{\delta}_{j}-\boldsymbol{\delta}_{M} \beta_{j}
$$

It is apparent that this modified exposure coefficient differs from the classic (Adler-Dumas) definition of exposure by the product of two easily identifiable terms, the exposure elasticity of the market and the market beta of the firm. 
that the firm that is not affected by exchange rate changes. However, a zero "residual" exposure implies a firm has the same "total" exposure as the market portfolio. Since it is unlikely that the exposure of the market portfolio will be exactly zero, the choice of including the market portfolio in the exposure regression directly impacts the absolute position and the interpretation of the resulting exposure estimates.

The exposure of the market portfolio will be driven by two factors. One is market-wide-"macroeconomic"factors or common non-cash flow related value impacts across all firms that happen to be correlated with the exchange rate over the estimation period. The other factor is the weighted-average value impacts that are directly driven by the exchange rate's impact on each firm's cash flows. Thus, the firms' "residual" exposure estimates are measured relative to both the common "macroeconomic" influences on value correlated with the exchange rate and the weighted-average cash flow changes arising from exchange rate movements.

Another methodological complication that arises with respect to the specification of equation (2) is the choice of the market portfolio. The common practice of using a value-weighted market gives more weight to the cash flow effects of large firms in term of the cash flow impact that is removed with the market exposure in equation (2). Large firms, as predicted by the corporate finance/industrial organization models of exposure are likely to see their cash flows (value) increase when the dollar falls. Small firms, on the other hand, tend to be domestically oriented and potentially net importers rather than sellers of international products. These same models generally predict that non-traded firms and importers tend to see their value rise when the dollar appreciates. If these predictions of the cash flow models of exposure are true, we would expect differences in the exposures of valueweighted versus equal weighted market portfolios. These differences would flow through to differences in the distributions of the "residual" exposures obtained from the estimation of equation (2). If this effect is not taken into account, it could lead to dramatically different interpretations about the impact of exchange rates on firms' cash flows. For example, Chow et al. (1997a) show that the CRSP value- and equal-weighted market portfolios exhibit different exposure to exchange rate movements.

\section{B.2. Return Horizon Issues}

In addition to the variable specification question, there is the methodological issue of the optimal length of the horizon over which to estimate exposure elasticities. Due to the common practice in the asset pricing literature of using monthly data to estimate model and test hypotheses, much of the empirical exchange rate exposure literature has used the monthly horizon for estimating exposures. Theoretical models assuming market efficiency 
and complete information suggest that the exposure should be independent of the horizon over which it is measured. In all cases, the market should impound the impact of an observed exchange rate change (and the resulting change in future exchange rate expectations) on the current and future expected cash flows of the firm into the current market price of the firm. However, given the complexity of exposures and the noise in high frequency observations in exchange rates relative to the persistence of low frequency movements, it is possible that exposures may be more accurately estimated over longer horizons.

For example, Bartov and Bodnar (1994) present evidence suggesting that firms with large consistent impacts of exchange rates reported in financial statements have a predictable stock price reaction around the earnings announcement based upon the exchange rate change over the previous quarter. This suggests that the market has difficulty determining the full impact of exchange rate changes in current and future cash flows and that full impact of an exchange rate changes is not instantaneously revealed in stock returns as investors wait for the firm to reveal the full extend of these effects. In support of a longer horizon view, evidence by Chow, Lee and Solt (1997b) suggests that the exposure of U.S. firms becomes much more detectable when the return horizon in extended out beyond 12 months. $^{9}$

Of course, differences in exposure estimates across return horizons may be due to different correlation between cash flows and exchange rates and/or different correlations between exchange rates and macro factors, drawing into question again the methodological choices discussed above. In other words, the influences of these two features might be interacted. Therefore, we consider them together in this study. In the next section, we examine both the influence of model specification with respect to the inclusion of a market portfolio return and changes in the return horizon on the resulting exposure estimates for a large sample of U.S. firms.

\footnotetext{
${ }^{9}$ Chow, Less and Solt (1997b) look at a measure of "total" exposure for a small set of U.S. multinational firms (N=213). We consider the impact of horizon issues in a variety of model specifications as well as for a much larger set of firms $(\mathrm{N}=910)$.
} 


\section{Data and Research Design}

The sample firms are selected from the 1996 CRSP NYSE/AMEX monthly stock file. To be included in the final sample, a firm must have monthly stock prices covering the period January 1977 through December 1996. This selection criterion results in 910 firms. Monthly return data on individual stock, value- and equal-weighted NYSE/AMEX market portfolios, and NYSE/AMEX size portfolios are retrieved from the CRSP files. The exchange rate variable, $X R$, is computed as the return on the Federal Reserve's U.S. Dollar trade-weighted index (Federal Reserve System, 1978). Figure 1 plots the exchange rate index over the sample period. By construction, an increase in the currency index corresponds to a real appreciation of the U.S. dollar. All nominal return data are converted to real measures using the monthly U.S. and G-10 foreign consumer price indexes from the IMF.

The estimation is undertaken for a 20 -year full period and four 5-year subperiods. The full period covers $77 / 01$ - 96/12, while the four sub-periods are 77/01 - 81/12, 82/01 - 86/12, 87/01 - 91/12, and 92/01 - 96/12. For each of these sample periods, we estimate currency exposures over different horizons. For horizon of one month, the estimation is based on non-overlapping monthly observations. Long horizon returns are continuously compounded over the corresponding interval and the estimation is based on overlapping monthly observations. The use of overlapping observations is common in long horizon regressions in which the variables of interests are generated by compounding the more finely sampled data to investigate the long term relation among the variables. Efficiency is improved as overlapping observations allow the time-series properties of the finely sampled data to be incorporated into the estimation (Richardson and Smith, 1991). We correct for the serial correlation induced by the use of overlapping observations using the method of Newey and West (1987). Moreover, we conduct all significance (twosided) tests at the $10 \%$ level, with the degree of freedom equals to the number of non-overlapping observations. The latter makes it more difficult to reject the null hypothesis of no exposure to exchange rate fluctuations. This conservative approach is adopted to ensure that our findings are not driven by a limited number of non-overlapping observations in long-horizon regressions, especially over the four five-year subperiods.

In the following section, we empirically examine the impact the possible differences in methodology (outlined in Section II.B) have on the estimation of exposure elasticities. In the process, we consider the implications of the different methodologies on the questions of the percentage of firms with a statistically significant exposure to exchange rates, as well as the proportion of these firms that gain versus lose from an appreciation of the U.S. dollar. In addition, we consider the stability of the exposure estimates across subperiods. 


\section{Empirical Findings}

\section{A. Total Exchange Rate Exposure: The Original Approach}

We begin by considering the exposure elasticity estimates based upon the original approach suggested by Adler and Dumas (1984). In this approach, market portfolio return is not included in the model and the exposure elasticity estimated for each firm is the "total" exposure elasticity. Thus for our sample of 910 U.S. firms, we estimate equation (3) for each firm for various return horizons of one month to sixty months for the full sample period (1976:1 - 1996:12) and return horizons ranging form one month to eighteen months for the four five-year subperiods.

$$
R_{j}=\alpha_{j}+\delta_{j} X R+\varepsilon_{j},
$$

$R_{j}$ is the inflation-adjusted stock return for firm $\mathrm{j}$ over the return horizon, and $X R$ is the percentage change in the real G-10 index value of the U.S. dollar over the same horizon as the stock return is measured. Since an increase in the exchange rate corresponds to a real appreciation of the U.S. dollar, a positive total exposure elasticity, $\delta_{j}$, implies that the real value of the firm increases when the U.S. dollar appreciates in real terms.

Table I reports the total exposure estimates for the 910 firms in our sample. For the full sample (period 0), the mean and median exposures are positive for the one month return horizon and increase through the six-month horizon, only to fall and become negative for horizons of 15 to 24 months, finally switching back to positive at 36month horizon and beyond. This significant shifting of the distribution of exposures over different return horizons is troubling as it suggests that the sign of the average total exposure elasticities is not independent of the return horizon used in the estimation. This variation seems at odds with the assumption that the market is informationally efficient. If the market is efficient in impounding the impact of any given exchange rate change on current and future cash flows into current market value of the firm, the exposure estimate should not change as a function of the length of time over which the relation is measured.

The last two columns of Table I indicate the percentage of firms with statistically significant exposure elasticities. In a similar fashion to the mean and median exposures, the percentage of firms with statistically positive and negative exposures varies noticeably over time. For the short horizons, the percentage of firms with significant positive exposures dramatically outnumbers the firms with significant negative exposures. In fact, for horizons up to 12 months, the number of firms with significant negative exposures never exceeds that suggested by statistical 
chance. Beyond the 12-month return horizons we find more significant negative exposures than positive exposures, only to see them equal out beyond 24-month return horizons.

The problem with the total exposures that has most bothered previous researchers is the total percentage of firms with significant exposure elasticities. At the common one-month horizon, we find only $14.6 \%$ of firms with exposure elasticities significant at the $10 \%$ level. Surprisingly, as the return horizon increases the total stays around $15 \%$ (with the notable exception of the 3-month return horizon), only increasing above $25 \%$ at horizons longer than 24 months.

Another interpretation problem with total exposure elasticities arises when looking at the subperiod. The mean exposures are generally significantly negative in the first two periods and significantly positive in the last two periods. Moreover, the means and medians are highly volatile across the four subperiods. The third subperiod, especially, produces positive exposure estimates that defy belief in terms of cash flow sensitivities. According to the results for 3 month and longer horizons, two-thirds of the 910 firms had significantly positive exposures for the period 1987 - 1991 while less than 10\% of these firms had positive exposures during the previous five-year period.

This variation in exposures across return horizons as well as subperiods can be seen visually in Figure 2. In the lower plot of Figure 2, it is possible to see the time-variation in the elasticity estimates. In the third subperiod, at the longer horizons, more than $90 \%$ of the firms have positive exposure estimates. While the distribution for the same firms in the previous subperiod had more than $50 \%$ of the firms with negative exposure estimates. The theoretical corporate finance models of exchange rate exposure determination require us to explain this shift in terms of the international activities of the firms or changes in the competitive structure of their markets. However, this shift appears too large, too sudden, and too widespread to be explained by cash flow-related changes in firm structures or changes in competitive environment.

This shift in exposure distribution highlights the major weakness of the total exposure estimates. Besides capturing the cash flow-related exchange rate exposure that the theoretical corporate finance models of exposure predict, total exposures also capture the relation between exchange rate changes and other (macroeconomic) factors that influence the market value of the firm. These may include identifiable effects like interest rates or unidentifiable factors, often referred to in asset pricing as "market sentiment." If the correlation of these macroeconomic factors and the exchange rate is large, they will mask the impact of exchange rate changes on the firms' cash flows, making the total exposure estimate a biased indicator of the actual exposure measure. 
Unfortunately, these macroeconomic factors are unlikely to be easily identifiable or to exhibit a consistent relation, for if they were, it would undoubtedly have been detected by researchers attempting to model and explain short-term exchange rate behavior. As this literature has not come to much great success, one is left to conclude that such a relation, as the one that drives the strong positive exposure in subperiod three, are most likely spurious. More troubling, with no way to separate out these (possibly spurious) macroeconomic exposure effects from firm-specific cash flow exposure effects, total exposures are an extremely noisy and potentially misleading way to identify the impact of exchange rate changes on firm's cash flows (or value).

\section{B. Equity Return Exchange Rate Exposures: The Common Practice}

In practice, researchers have always estimated residual exposure elasticities by including a market portfolio in the model specification. This inclusion of a market portfolio has two beneficial effects. First, as the market portfolio is the best variable we know of to explain stock return, its inclusion in the exposure model reduces the residual variance of the regression and improves the precision of the exposure elasticity estimates. Second, the market return implicitly acts as a control for the macroeconomic factors that are correlated with the exchange rate and affect the valuation of all firms in the market. This improves our ability to interpret the resulting exposure elasticities in terms of the corporate finance based models. However, as discussed in Section II, the inclusion of the market portfolio changes the interpretation of the estimated exposure elasticity to a residual exposure, rather than a total exposure. In this regard, care must be made in interpreting the economic meaning of a firm with a zero exposure. A zero exposure no longer implies that the firm's value is independent of exchange rates, rather that the

firms value is affected in the same degree as the market portfolio. A similar logic applies when interpreting positive or negative residual exposure estimates.

To examine the impact of including the market portfolio in the exposure regression we estimate equation (4) for our sample firms across horizons and subperiods.

$$
R_{j}=\alpha_{j}+\gamma_{j} X R+\beta_{j} R_{V W M}+\varepsilon_{j}
$$


In this case, $\mathrm{R}_{\mathrm{VWM}}$ is the return to the CRSP value-weighted market, which is commonly used in the literature. The other variables are the same as in the previous estimation. The coefficient $\gamma_{\mathrm{j}}$ is firm j's "residual" exposure elasticity.

Table II shows summary statistics of the distributions of the estimated market betas and exchange rate exposure elasticities by horizon and subperiod. The average market beta of the sample firms is close to one and the majority of the firms have a significantly positive beta as expected. However, for horizons of 36 months or longer, a small number of the firms are found to have a statistically negative beta.

For the exchange rate exposure elasticity estimates, we see several different features as compared to the total exposure elasticities in Table I. First, for the full sample (period 0) the mean and median exposures are positive at all horizons. In fact, the mean and median exposure elasticity estimates increase monotonically with the return horizon. We also see that at all horizons, the percentage of firms with significant positive exposures outnumber the percentage of firms with significant negative exposures more than two-to-one. This suggests that when the U.S. dollar appreciates, substantially more of these firms experience increases in value relative to the market than suffer decreases in value relative to the market. As for the total percentage of firms with statistically significant exposure estimates, we see the improvement resulting form the inclusion of the market portfolio. The percentage of firms with significant exposure estimates is higher than that reported in Table I; however, the improvements are rather modest. The total percentage remains roughly constant at around 20-25\% for horizons of one month out to 21 months. ${ }^{10}$ These results of a positive average exposure and 20-25\% significance of the exposure estimates are consistent with the results documented in previous exposure studies estimating an exposure model like equation (4) using monthly returns (e.g., Jorion (1990), Bodnar and Gentry (1993), Allayannis (1995), and Wong (1999)).

The ability to identify a greater percentage of more significant exposures does not increase noticeably until the return horizon is extended out to 24 months or longer. For 24 months, the percentage of firms with significant exposures increases to $29 \%$, increasing up to $60 \%$ for 60 -month horizon. This suggests that there may be a long lag time until the full incorporation of exchange rate changes into firm value. This result of improved ability to identify significant exposures at long horizons is consistent with the finding of Chow, Lee, and Solt (1997b) who find a

\footnotetext{
${ }^{10}$ Note that the standard errors on these exposure estimates are corrected for serial correlation induced by the use of overlapping observations. Moreover, given the unknown small sample properties of the standard error adjustments, the $10 \%$ levels used to determine statistical significance were based upon the number of non-overlapping observations rather than the number of overlapping observations.
} 
noticeable increase in the percentage of multinational firms with statistically significant exposures only at three and four year horizons.

The results for the mean and median exposures for the subperiods are similar to those for the full period. Except for a few cases, the mean and median estimates are positive in all periods and all horizons. In general, more firms are found to be significantly positively exposed to dollar appreciations than negatively exposed. However, in subperiod 1 (77/01-81/12), the percentage of firms with negative currency exposure elasticities is higher than that with positive exposures for the longer horizons. The subperiods do seem to improve the ability to estimate statistically significant exposures as, for horizons longer than 3-months, the percentages of firms with a significant exposure estimate (positive or negative) in the subperiods is higher than the corresponding numbers in the full period.

Figure 3 displays a plot of the 10th, 25th, 50th, 75th, and 90th percentiles of the estimated currency exposures of all the sample firms by horizon. In the top plot for the full sample period, it is clear that as the horizon lengthens from 1 month to 60 months, both the median and the spread of the estimates increase steadily. The same basic pattern holds for the sub-period analyses in the bottom plot. However, it is important to note that the significant jump in the distribution of "total" exposures for subperiod three, seen in Figure 2, is not as apparent for subperiod 3 in Figure 3. This demonstrates that the residual exposure estimates are more stable over time than the "total" exposure estimates, because the market portfolio removes much of the common (macroeconomic) value correlation with the exchange rate from the exposure estimates.

One troubling fact about these "residual" exposure elasticities estimated using the value-weighted market portfolio return is that they are mostly positive. This implies that most firms experience gains (relative to the market) when the U.S. dollar appreciates. As a measure of the cash flow sensitivity of these firms to the exchange rate, this interpretation is at odds with the results of studies on the relation of reported profits of U.S. corporations with the exchange rate. Clarida (1992) and Hung (1992) present evidence to suggest that U.S. manufacturing profits are significantly negatively affected by an appreciation of the U.S. dollar. For example, Hung (1992) reports that the upward swing in the dollar during the 1980s resulted in a profit loss to U.S. firms of $\$ 23$ billion per year. Uctum (1996) estimates that a $1 \%$ depreciation of the U.S. dollar leads to a nearly $1 \%$ increase in the dollar value of overseas profits of U.S. corporations. Taken together this evidence would lead one to expect that if stock prices 
were directly related to cash flows, the exchange rate exposures estimated from equity prices would also reveal this negative relation. We investigate this puzzle in more depth in the next section.

\section{Equity Return Exchange Rate Exposures using the Equal-Weighted Market Portfolio}

Since most studies look at average residual exposure giving each estimate equal weight, it might be sensible to also give each firm equal weight in the market portfolio included in the specification of the exposure model represented by equation (2). The use of the equally weighted market portfolio treats each firm's exposure equally in terms of determining the market exposure. This fact leads to the convenient theoretical fact that the residual exposures across all the firms in the market must sum to zero. We re-estimate equation (4) using the CRSP equal-weighted market index as the market portfolio. Again, we do the estimation for the range of return horizons and subperiods. Summary statistics for the estimates of the EW market based exposure elasticities are reported in Table III, along with the comparable results from the value-weighted market exposure model.

Comparisons of the exposure estimates that controlled for the value-weighted (VW) and equal-weighted (EW) markets reveal several interesting results. For the full sample results (denoted as period 0) when the EW portfolio is used, we find that both the mean and median exposure estimates at all horizons are now negative; they become more negative as the return horizon increases; there has also been a reversal in the percentage of firms with statistically significant negative versus positive exposures; and significant negative exposures to dollar appreciations outnumber positive exposures nearly two-to-one. This appears more consistent with the results of aforementioned studies that relate profits and exchange rate changes.

However, the use of the EW market does not improve the total number of firms with statistically significant exposures. As before, for return horizons out to 21 months, we find between $20-25 \%$ of firms with statistically significant exposure elasticities. Again, at 24 months and beyond we see a greater ability to detect significant exchange rate exposures (this is despite our conservative use of the number of non-overlapping observations as the degrees of freedom for the test).

The subperiods tell us a similar story. The mean and median exposures for most subperiods are negative, especially at short return horizons. As the return horizons grow, the means (and occasionally the median) for the first subperiod become statistically positive. In all subperiods but the first, the percentage of firms with statistically significant negative exposures to dollar appreciations outnumbers those with significant positive exposures. 
Figure 4 plots the distribution of the exposure estimates with an EW market included by horizons and subperiods. Comparing Figure 4 with Figure 3, one can observe that (except for subperiod 1) the distributions are shifted downward and the median exposures are negative. These comparisons are striking. We obtain a completely different economic implication about the exposures of the sample firms based upon the choice of the market portfolio included in the empirical model. Clearly, the choice of the market portfolio does make a different in one's inference. In the next subsection, we look into the reason behind why different constructions of the market portfolio have such a measurable impact on the resulting exposure elasticity estimates.

\section{Comparing Exposures of the Market Portfolios}

As we mention it in Section II.B, the currency exposure estimated in equation (4) is a residual in that each firm's estimated exposure is the difference between its total exposure and the market's exposure to the exchange rate times the firm's market beta. Thus, the difference in the two sets of results must arise from differences in the VW and EW markets' exposures to the exchange rate index. Given that the exposure elasticities using the VW market return are more positive than those estimated using the EW market return, it must be true that the EW market itself has a more positive exposure at all horizons than the VW market portfolio.

Indeed, Table IV indicates that for all horizons for the full sample, the estimated currency exposures of the CRSP EW market portfolio is uniformly larger (more positive) than those of the VW portfolio. Although the differences do not reach conventional significance levels until the 36-month horizon, the differences are economically significant at all horizons. The smallest difference is at the one-month horizon when it is 0.191 , which is about twice as large as the mean or median residual exposure elasticity of our sample firms. The difference grows monotonically with the length of the return horizon, reaching 0.715 at 60 months. Although both market portfolios start with a positive exposure to dollar appreciations, the VW market quickly turns negative by nine months and becomes significantly negative by 21 months. The EW market exposure begins with a large positive exposure and decreases out through 21 months, but always remains positive. It jumps up sharply at 24 months and by 36 months onward, it is significantly positive at the 10 percent level.

Across the four subperiods, only in the first subperiod do we find that the exposure of the EW market is less positive than the exposure of the VW market. The difference in exposure elasticity is most noticeable in the final two subperiods, where despite the limited number of observations, we find the difference statistically 
significant from the nine-month return horizon through to the 18-month return horizon. Figure 5 plots five-year horizon rolling estimates of the exposures of the CRSP VW and EW market portfolios at horizons of one, three, six and twelve months. From the plots, it is easy to see the variability of the market exposures over time. The exposures are all negative in the early part of the sample period and become very positive in the mid to late 1980s and decrease again into the 1990s. It can also be seen by comparing the two plots that the EW market is almost everywhere more positively exposed to exchange rate movements than the VW market.

\section{E. Exposure and Portfolio Size}

Since the EW market portfolio is more influenced by small firms, it suggests that an explanation for the difference in the exchange rate exposures of the differently weighted CRSP market portfolios is that smallcapitalized firms are more positively affected by dollar appreciations than large firms are. This explanation does have some intuitive appeal because of general differences in the operating structures of large and small firms. In particular, large firms are more likely to be multinationals or large exporters and have net foreign currency revenues

(long foreign currency position) and gain when the U.S. dollar depreciates. On the other hand, small firms are more likely to be non-traded goods producers and therefore potential net importers (short foreign currency position) who gain when the U.S. dollar appreciates. ${ }^{11}$

To explore this possible explanation in general, we estimate the total exchange-rate exposure elasticities of the CRSP capital-based decile portfolios. Summary statistics of the estimated exposure elasticities for the Size 1 (largest), Size 4, Size 7 and Size 10 (smallest) decile portfolios are reported in Table V. Figure 6 displays the results in visual form as a plot. For the full sample (period 0), the portfolio exposures are monotonic in terms of the market capitalization at all horizons. The Size 1 (largest) portfolio, starts with an exposure elasticity of zero and becomes progressively more negative, becoming significantly negative at the 21 months horizon. In contrast, the Size 10 portfolio starts off with a significantly positive exposure elasticity, which decreases slightly and becomes insignificant through 21 months and then increases rapidly becoming significant again at 24 months onward. The impressive monotonicity of the exposures across size breaks down somewhat when we look at subperiods. In the first subperiod, across return horizons of 9 to 18 months, we actually see the pattern reversed. Typically the large firms have the more positive exposures and the smallest firms have the most negative exposures (at least for return 
horizons beyond 6 months). ${ }^{12}$ While the second subperiod generally sees the Size 4 portfolio having the most negative exposure elasticities, the monotonicity full sample pattern reappears in subperiods 3 and 4 . However, in these subperiods, the exposures of all the size portfolios are everywhere positive. Table $\mathrm{V}$ also reports tests on the significance of the difference between the exposure of each of the smaller portfolios and that of the Size 1 portfolio. Generally, the difference between the exposures of the Size 1 and Size 10 portfolios are statistically meaningful. In the subperiods, all the differences are significant for the last subperiod.

To further investigate whether this size-exposure relation is due to systematic different in foreign cash flow positions of different sized firms arising from operational differences, we create our own size portfolios from the subset of firms that appear on the Compustat geographic segment database. This sample is only a subset of the CRSP decile portfolios studied above as not all firms are reported on the Compustat geographic segment database and its data only begins in 1979. Nonetheless, we construct ten market capitalization portfolios from these firms based upon their market capitalization in the beginning of the year. For each sample year and size decile, we further divided the firms into three sub-portfolios, high, low, or zero, based upon their reported foreign-and-export sales ratio. We compute foreign-and-export sales ratio as the sum of foreign sales and export sales scaled by total firm sales. This is appropriate as the estimated exposure elasticity is as a percentage of firm value. The portfolios' monthly returns are calculated as the value-weighted average of the returns for the firms in the sub-portfolios.

Table VI reports some summary statistics on nature of the Size 1, 4, 7, and 10 sub-portfolios, conditional on the foreign sales ratio. There are a total of 103 and 220 firms in 1979 and 1996, respectively, in each of the ten size deciles (results not reported in the table). The (time-series) average number of firms without foreign activities (zero \%FGN sales) increases as we move from the large-capitalized Size1 to the low-capitalized Size 10 group. For the high (or low) foreign-and-export-sales portfolios, the value-weighted average of foreign-and-export sales percentage decreases from $50.4 \%$ (14.8\%) in decile 1 to $31.5 \%$ (0.0\%) in decile 10 . Taken together, these statistics are consistent with our earlier conjecture about the characteristics of the CRSP capital-based decile portfolios (i.e., size is correlated with the extent of multinationality).

\footnotetext{
${ }^{11}$ There seems to be some recognition of this idea in the market. Several business press articles have made reference to a large/small cap stock price effect with respect to exchange rates. (citations)

12 One explanation for this reversal of the relation between size and exposure is that the first subperiod (1977-1981) was the noted "small cap" market boom on the U.S. During this period, small cap stocks significantly outperformed large cap stocks. Moreover, during this period, the US dollar depreciated on average, leading to the observed stronger negative exposure for the small cap stocks.
} 
Table VII reports and Figure 7 displays visually the "total" exposure estimates for these size and foreign sales conditioned portfolios. The cash flow model of exposure would suggest negative exposures among those portfolios with the high foreign sales and the positive exposures among those portfolios with zero foreign sales, regardless of the size of the firms. However, the results show that the largest firms (Size 1) exhibit mostly negative exposure estimates while the smaller firms (Size 7 and 10) always exhibit positive exposure estimates regardless of the degree of foreign operations. The fanning of exposures estimates across size portfolios, shown earlier in Figure 6, still exists for all conditional foreign sales groupings in Figure 7. As a simple indication of the importance of firm size relative to the foreign sales ratio for exposure, notice that the large firm (Size 1) Zero Foreign Sales portfolio exposures are everywhere more negative than the exposure elasticities of the smaller (Size 4, 7 and 10) High Foreign Sales portfolios, despite each of these having average foreign sales of over 30\%. Finally, as a simple test of whether firm size matters for the exposure once one controls for cash flow effect (using the foreign sales ratio) the columns labeled "Diff" in Table VII report the significance level of the tests of each exposure relative to that for the Size 1 portfolio. It is clear that, especially for the Size 10 portfolio, many of the exposure differences across firm size are statistically significant, after controlled for cash flow effect.

\section{Size Effect in Exchange Rate Exposures}

\section{A. Size Effect in Firm-Level Exposures}

To examine whether the portfolio-level size effect documented above carries to the firm-level exposure estimates, we run a cross sectional regression of our sample firms' exchange rate exposure estimates on the firms' foreign-and-export sale ratio and market value. Because the exposures estimates are estimated over a period of time, we use the average foreign-and-export sales ratio and average market value over the same time period. The foreignand-export sales ratio is an accounting proxy for the firm's cash flow exposure. While cash flow models of exposure suggest that the exposure should be related to "net" foreign currency position (see, e.g., Marston (1999)), because firms only report foreign currency revenues and not costs, we have no choice except to use this crude proxy for the underlying determinant of exposure. ${ }^{13}$

The results of this cross sectional regression for the full sample are displayed in Table VIII. It is immediately apparent that at all horizons, both the export plus foreign sales ratio (\%FGN Sales) and firm size

\footnotetext{
${ }^{13}$ Foreign sales ratios have been identifies as an important determinant of exposures in previous cross-sectional tests (see, e.g., Jorion (1990)).
} 
(MVE) are important for explaining cross sectional differences in exposures. The foreign-and-export sales ratio is everywhere significantly negatively related to exposure, indicating that greater foreign sales result in a more negative exposure. The negative relation implies that the firm experiences higher returns when the dollar depreciates, which is consistent with economic intuition as dollar depreciations increases the value of foreign cash flow streams. On the other hand, the significantly negative coefficient on MVE indicates that larger firms have exposures that are more negative, independent of their foreign sales ratio, just as we saw in the portfolio level analysis above. It is interesting to note from the t-statistics that at short horizons, market value (MVE) is more significant for explaining cross section variation in exposures than the foreign sales ratio (\% FGN Sales). In all cases, however, these two variables only explain a small percentage of the total cross-sectional variability of exposure estimates. The adjusted $\mathrm{R}^{2}$ are only around $5-6$ percent.

This size-exposure relation indicates a potential problem for studies examining cross sectional differences in exposures across firms (e.g., Jorion (1990), Allayannis and Ofek (1998) and Wong (1999)). Specifically, a failure to control for size in the cross sectional regression causes a correlated omitted variable problem, which will misstate the significance of other variables in the regression. Hence, size should be controlled for if one uses the VW or EW market controlled exposure estimates. Alternatively, one should use exposure estimates that are free of the size effect, as we discuss next.

\section{B. Controlling for the Size Effect in Exposures}

Having demonstrated a size effect in exposures that complicates their interpretation as measures of exchange rate related cash flow impact, we suggest a method of estimating exposures that mitigates this problem. Our approach is to use an appropriate size portfolio as the control for the "macroeconomic" factors discussed earlier. Doing so allows us to control for both the macroeconomic factors that influence firm value and the size effect in currency exposure. For practical purposes, we use the CRSP capital-based decile portfolios as the size portfolios. Thus, instead of using a common market portfolio return in the exposure regressions, we use a matching CRSP size decile portfolio return for each firm.

Table IX shows summary statistics of the distributions of the exposure elasticities for our original sample of 910 firms, controlling for the matching CRSP Cap-based portfolio. The distributions of exposures are similar, albeit shifted even slightly more to the negative side, to those reported in Table III using the CRSP EW market 
portfolio. For the full sample period (period 0), the mean and median exposures are statistically negative at all horizons and the percentage of firms with significant negative exposures dramatically outnumbers that with significant positive exposures. Regardless of sample period and horizon, the average exposure (beta) to the matching CRSP Cap-based portfolio is positive and slightly less than one. Further, most of the firms are significantly positively exposed to the size-matched portfolio, especially at short horizons.

The subperiod results are similar to those for the full period. The mean and median exchange rate exposure estimates are always negative in all periods and all horizons, except for the fourth subperiod. With a few exceptions, the percentage of firms with statistically significant negative exposures to dollar appreciations outnumbers those with significant positive exposures.

To demonstrate that this approach of using a size based market control portfolio reduces the relation between the estimated exchange rate exposures and firm size, we cross-sectionally regress the exposures on foreign sales and firms size as above. The results of this regression are shown in Table X. From the table, one can immediately see, that with the exception of the one, three, and sixty month horizons, MVE is no longer significantly related to the exchange rate exposure estimate. In all cases, the foreign sales ratio remains significantly negatively related to exposure as before. However, in comparing the results here with those of Table VIII, the foreign sales ratio is more strongly related to the size decile controlled exposures than the VW market controlled exposures. This suggests that our new specification for estimating exposures produces results that possess less of the anomalous relation with firm size and a closer relation to the theoretically predicted cash flow measures.

In sum, Tables IX and X show that our proposed approach generates exchange rate exposure estimates that exhibit two appealing properties. First, they are generally negative, which is consistent with what one would expect for the estimates to be interpreted as a measure of exchange rate related cash flow impact. Second, they are less affected by the size effect that influences the traditional exposure estimates.

\section{Summary and Concluding Remarks}

We investigate the importance of model structure on the empirical estimation of exchange rate exposure using stock return regressions on a large sample of U.S. firms over the twenty-year period 1977 - 1996.

First, we show that the inclusion of a market return variable on the right-hand side of the regression model

for estimating exchange rate exposure results in the exposure estimates being "residual" exposures, deviations from 
the market portfolio's exposure. Hence, if the market exposure is non-zero, the interpretation of finding zero exposure for a firm cannot be made in an absolute term. This is important as the empirical result of having "zero" exposure is often given economic meaning of a firm that is not affected by exchange rate changes. Moreover, if different constructions of the market portfolio have different correlations with the exchange rate, the choice of the market portfolio will become a crucial issue. In summary, our findings suggest that the choice of a market portfolio directly impacts the nature and interpretation of the resulting exchange rate exposure estimates. This methodological problem appears to be the root of the contradictory results of the sign of the average impact of exchange rate changes on stock returns and the sign of the average impact of exchange rates changes on profits.

Second, without including the market portfolio in the regression model, we find that the exchange rate exposures exhibit significant time variation that appears too large to represent changes in cash flow sensitivities. We believe that this time variation is likely due to time varying (possibly spurious) correlations of the exchange rate with macroeconomic factors, such as interest rates or the expected market risk premium, that affect the valuation of all firms. We provide some evidence that without controlling for this "macro-effect" in the exposure regressions (by including a market portfolio); the time-variation is transferred to the estimated "total" equity exposures of the individual firms. Third, we document size effect in exchange rate exposure. In particular, we find an inverse relation between market capitalization and exchange rate exposure (i.e., small-capitalized firms are more positively exposure to exchange rate fluctuations). The documented size effect remains even after we control for the extent of firms' involvement in exchange rate sensitive activities, using foreign and exports sales as a percentage of total firm sales.

Finally, we suggest an alternative specification for exposure estimation to reduce the anomalous relation with firms size. To this end, we replace the market portfolio return in the exposure regression with the return on the CRSP capitalization based decile portfolios. We demonstrate that these exposure estimates are cross-sectionally less related to firm size than the exposures estimates obtained using the VW market return as a control variable.

Although, we do not completely eliminate the relation between exposures and firm size at all horizons using this new approach, we demonstrate that these exposures are more closely related to foreign sales ratios, as is predicted by the fundamental cash flow models of the firm. 


\section{REFERENCES}

Adler, Michael and Bernard Dumas. 1984. Exposure to currency risk: Definition and measurement. Financial Management 13: 41-50.

Allayannis, George. 1995. Exchange rate exposure revisited. Working paper, Stern School of Business, New York University.

1996. The time-variation of the exchange rate exposure: An industry analysis. Working paper, Darden Graduate School of Business, University of Virginia.

and Eli Ofek. 1996. Exchange rate exposure, hedging, and the use of foreign currency derivatives. Working paper, Stern School of Business, NYU.

Bartov, Eli and Gordon M. Bodnar. 1994. Firm valuation, earnings expectations, and the exchange-rate exposure effect. Journal of Finance 49: 1755-1785.

Bodnar, Gordon M. and William M. Gentry. 1993. Exchange rate exposure and industry characteristics: Evidence from Canada, Japan, and the USA. Journal of International Money and Finance 12: 29-45.

Bodnar, Gordon M. and Richard Marston. 1996. 1995 Survey of Derivatives Usage by U.S. Non-Financial Firms. Philadelphia, PA: The Wharton School and CIBC Wood Gundy.

Chow, Edward H., Wayne Y. Lee and Michael E. Solt. 1997a. The exchange-rate risk exposure of asset returns. Journal of Business 70(1): 105-123.

Chow, Edward H., Wayne Y. Lee and Michael E. Solt. 1997b. The economic exposure of U.S. multinational firms. The Journal of Financial Research 20(2): 191-210.

Clarida, R. 1992, The Real Exchange Rate and U.S. Manufacturing Profits: A Theoretical Framewoek with Some Empirical Support, Federal Reserve Bank of New York, Research Paper No. 9214.

Federal Reserve System. 1978. Index of the weighted-average exchange value of the U.S. dollar: Revision. Federal Reserve Bulletin (August): 700.

Flood, Eugene Jr. and Donald R. Lessard. 1986. On the measurement of operating exposure to exchange rates: A conceptual approach. Financial Management (Spring): 25-37.

Froot, Kenneth, David Scharfstein and Jeremy Stein. 1993. Risk management: Coordinating investment and financing policies. Journal of Finance 48: 1629-1658.

Gonedes, Nicholas. 1973. Evidence on the information content of accounting numbers: Accounting-based and market-based estimates of systematic risk. Journal of Financial and Quantitative Analysis 8 (June): 407-444.

Greene, William H. 1990. Econometric Analysis. New York, NY: Macmillan Publishing Company.

Hansen, Lars Peter. 1982. Large sample properties of generalized method of moments estimators. Econometrica 50: 1029-1054.

Hekman, Christine R. 1985. A financial model of foreign exchange exposure. Journal of International Business Studies (Summer) 16: 83-99.

Hodder, James E. 1982. Exposure to exchange-rate movements. Journal of International Economics 13: 375-386.

Hung, J., 1992, Assessing the Exchange Rate's Impact on U.S. Manufacturing Profits, Federal reserve Bank of New York Quarterly Review, 4 Winter, pp. $44-63$.

Levi, Maurice. 1993. International Finance: Financial Management and the International Economy. NY: McGrawHill. 
Lewent, Judy C. and A. John Kearney. 1990. Identifying, measuring, and hedging currency risk at Merck. Journal of Applied Corporate Finance 2.

Jorion, Philippe. 1990. The exchange-rate exposure of U.S. multinationals. Journal of Business 63: 331-345.

Marston, Richard. 1998. The effects of industry structure on economic exposure. Working Paper. Weiss Center for International Financial Research, The Wharton School.

Newey, Whitney K. and Kenneth D. West. 1987. A simple positive semi-definite, heteroscedasticity and autocorrelation consistent covariance matrix. Econometrica 55: 703-708.

Palia, Darius and Jacob Thomas. 1996. Exchange rate exposure and firm valuation: New evidence for market efficiency. Working Paper, Graduate School of Business, Columbia University.

Richardson, Matthew and Tom Smith. 1991. Tests of financial models in the presence of overlapping observations. Review of Financial Studies 4: 227-224.

Smith, Clifford W. and René M. Stulz. 1985. The determinants of firms' hedging policies. Journal of Financial and Quantitative Analysis 20: 391-405.

Shapiro, Alan C. 1974. Exchange rate changes, inflation and the value of the multinational corporation. Journal of Finance 30: 485-502.

Stulz, Rene M. 1984. Optimal Hedging Policies. Journal of Financial \& Quantitative Analysis 19:127-140. and Rohan Willamson. 1997. Identifying and Quantifying Exposures. Risk Publications.

Uctum, M. 1996, The Exchange Rate's Impact on Overseas Profits of U.S. Corporations, New York FED mimeo.

Wong, M.H. Franco. 1999. The association between SFAS 109 derivatives disclosures and the foreign exchange risk exposure of manufacturing firms. Journal of Accounting Research (forthcoming). 
Table I

Descriptive Statistics on Equity Return Total Exchange Rate Exposure Estimates (N=910)

Currency exposures are estimated using monthly overlapping observations, with the number of overlapping observations for each horizon reported under the column titled "T." The percents of significantly negative and positive estimates are based on a two-sided t-test at the $10 \%$ significant level, with the degree of freedom equals to the number of non-overlapping observations. Period 0 covers 7701-9612. The four sub-periods (1-4) are 77018112, 8201-8612, 8701-9112, and 9201-9612.

Currency exposure

\begin{tabular}{|c|c|c|c|c|c|c|}
\hline \multirow[b]{2}{*}{$\begin{array}{l}\text { Horizon } \\
\text { (months) }\end{array}$} & \multirow[b]{2}{*}{ Period } & \multirow[b]{2}{*}{$\mathrm{T}$} & \\
\hline & & & Mean & Median & $\begin{array}{c}\text { Negative } \\
(\%)\end{array}$ & $\begin{array}{c}\text { Positive } \\
(\%)\end{array}$ \\
\hline 1 & 0 & 240 & $0.132^{\mathrm{a}}$ & 0.098 & 3.6 & 11.0 \\
\hline 3 & 0 & 238 & $0.256^{\mathrm{a}}$ & 0.202 & 3.0 & 24.3 \\
\hline 6 & 0 & 235 & $0.241^{\mathrm{a}}$ & 0.188 & 2.5 & 18.9 \\
\hline 9 & 0 & 232 & $0.107^{\mathrm{a}}$ & 0.075 & 4.8 & 10.0 \\
\hline 12 & 0 & 229 & $0.031^{\mathrm{c}}$ & 0.012 & 6.9 & 7.5 \\
\hline 15 & 0 & 226 & -0.009 & -0.033 & 8.1 & 6.5 \\
\hline 18 & 0 & 223 & $-0.050^{\mathrm{b}}$ & -0.073 & $\begin{array}{c}0.1 \\
10.5\end{array}$ & 5.6 \\
\hline 21 & 0 & 220 & $-0.084^{\mathrm{a}}$ & -0.105 & 13.8 & 6.7 \\
\hline 24 & 0 & 217 & $-0.050^{\mathrm{b}}$ & -0.093 & 14.0 & 9.5 \\
\hline 36 & 0 & 205 & $0.097^{\mathrm{a}}$ & 0.005 & 15.5 & 16.8 \\
\hline 48 & 0 & 193 & $0.082^{\mathrm{b}}$ & -0.030 & 23.3 & 20.5 \\
\hline 60 & 0 & 181 & $0.186^{\mathrm{a}}$ & 0.031 & 24.4 & 28.1 \\
\hline 1 & 1 & 60 & $-0.102^{\mathrm{a}}$ & -0.141 & 6.8 & 0.9 \\
\hline 1 & 2 & 60 & -0.014 & -0.009 & 4.3 & 3.2 \\
\hline 1 & 3 & 60 & $0.387^{\mathrm{a}}$ & 0.323 & 0.4 & 15.8 \\
\hline 1 & 4 & 60 & $0.262^{\mathrm{a}}$ & 0.191 & 4.0 & 15.7 \\
\hline 3 & 1 & 58 & $-0.165^{\mathrm{a}}$ & -0.198 & 8.2 & 2.7 \\
\hline 3 & 2 & 58 & $-0.192^{\mathrm{a}}$ & -0.176 & 11.1 & 2.3 \\
\hline 3 & 3 & 58 & $1.114^{\mathrm{a}}$ & 1.035 & 0.0 & 63.1 \\
\hline 3 & 4 & 58 & $0.318^{\mathrm{a}}$ & 0.215 & 8.1 & 23.8 \\
\hline 6 & 1 & 55 & $-0.059^{b}$ & -0.016 & 11.4 & 9.8 \\
\hline 6 & 2 & 55 & $-0.231^{\mathrm{a}}$ & -0.208 & 18.4 & 4.6 \\
\hline 6 & 3 & 55 & $1.330^{\mathrm{a}}$ & 1.231 & 0.1 & 69.5 \\
\hline 6 & 4 & 55 & $0.445^{\mathrm{a}}$ & 0.353 & 4.8 & 24.1 \\
\hline 9 & 1 & 52 & $-0.144^{\mathrm{a}}$ & -0.037 & 17.0 & 14.0 \\
\hline 9 & 2 & 52 & $-0.207^{\mathrm{a}}$ & -0.221 & 20.7 & 7.3 \\
\hline 9 & 3 & 52 & $1.569^{\mathrm{a}}$ & 1.450 & 0.2 & 72.5 \\
\hline 9 & 4 & 52 & $0.527^{\mathrm{a}}$ & 0.499 & 7.8 & 29.1 \\
\hline 12 & 1 & 49 & $-0.078^{\mathrm{b}}$ & 0.027 & 16.9 & 17.8 \\
\hline 12 & 2 & 49 & $-0.216^{\mathrm{a}}$ & -0.264 & 27.9 & 8.6 \\
\hline 12 & 3 & 49 & $1.416^{\mathrm{a}}$ & 1.267 & 2.0 & 59.8 \\
\hline 12 & 4 & 49 & $0.517^{\mathrm{a}}$ & 0.472 & 11.8 & 32.3 \\
\hline 15 & 1 & 46 & 0.015 & 0.113 & 14.8 & 21.9 \\
\hline 15 & 2 & 46 & $-0.224^{\mathrm{a}}$ & -0.286 & 34.7 & 9.6 \\
\hline 15 & 3 & 46 & $1.293^{\mathrm{a}}$ & 1.141 & 3.1 & 65.9 \\
\hline 15 & 4 & 46 & $0.518^{\mathrm{a}}$ & 0.469 & 13.4 & 37.7 \\
\hline 18 & 1 & 43 & 0.017 & 0.116 & 15.9 & 21.5 \\
\hline 18 & 2 & 43 & $-0.209^{a}$ & -0.284 & 34.5 & 11.3 \\
\hline 18 & 3 & 43 & $1.302^{\mathrm{a}}$ & 1.119 & 6.2 & 65.1 \\
\hline 18 & 4 & 43 & $0.506^{\mathrm{a}}$ & 0.463 & 14.2 & 37.6 \\
\hline
\end{tabular}

a, b, and c denote statistically significant at the 1\%, 5\%, and 10\% level, respectively, using a two-tailed $t$-test. 
Table II

\section{Descriptive Statistics on Equity Return Residual Exchange Rate Exposure Estimates} with Value Weighted Market Portfolio (N=910)

Currency exposures are estimated using monthly overlapping observations, with the number of overlapping observations reported under the column titled "T." The percents of significantly negative and positive estimates are based on a two-sided t-test at the $10 \%$ significant level, with the degree of freedom equals to the number of nonoverlapping observations. Period 0 covers 7701-9612. The four sub-periods (1-4) are 7701-8112, 8201-8612, 87019112, and 9201-9612.

\begin{tabular}{|c|c|c|c|c|c|c|c|c|c|c|}
\hline \multirow[b]{2}{*}{$\begin{array}{l}\text { Horizon } \\
\text { (months) }\end{array}$} & \multirow[b]{2}{*}{ Period } & \multirow[b]{2}{*}{$\mathrm{T}$} & \multicolumn{4}{|c|}{ (VW) Market beta } & \multicolumn{4}{|c|}{ Currency exposure } \\
\hline & & & Mean & Median & $\begin{array}{c}\text { Negative } \\
(\%)\end{array}$ & $\begin{array}{c}\text { Positive } \\
(\%)\end{array}$ & Mean & Median & $\begin{array}{c}\text { Negative } \\
(\%)\end{array}$ & $\begin{array}{c}\text { Positive } \\
(\%)\end{array}$ \\
\hline 1 & 0 & 240 & $1.010^{\mathrm{a}}$ & 1.031 & 0.0 & 100.0 & $0.104^{\mathrm{a}}$ & 0.071 & 6.7 & 15.8 \\
\hline 3 & 0 & 238 & $1.066^{\mathrm{a}}$ & 1.086 & 0.0 & 100.0 & $0.132^{\mathrm{a}}$ & 0.076 & 8.6 & 22.6 \\
\hline 6 & 0 & 235 & $1.042^{\mathrm{a}}$ & 1.025 & 0.0 & 99.0 & $0.157^{\mathrm{a}}$ & 0.104 & 5.9 & 18.4 \\
\hline 9 & 0 & 232 & $1.009^{\mathrm{a}}$ & 0.965 & 0.0 & 95.6 & $0.139^{\mathrm{a}}$ & 0.105 & 6.7 & 16.8 \\
\hline 12 & 0 & 229 & $0.985^{\mathrm{a}}$ & 0.935 & 0.0 & 90.3 & $0.143^{\mathrm{a}}$ & 0.116 & 7.3 & 16.2 \\
\hline 15 & 0 & 226 & $0.973^{\mathrm{a}}$ & 0.915 & 0.0 & 85.9 & $0.167^{\mathrm{a}}$ & 0.127 & 7.2 & 17.4 \\
\hline 18 & 0 & 223 & $0.963^{\mathrm{a}}$ & 0.902 & 0.0 & 81.3 & $0.183^{\mathrm{a}}$ & 0.149 & 6.9 & 17.0 \\
\hline 21 & 0 & 220 & $0.952^{\mathrm{a}}$ & 0.933 & 0.0 & 74.2 & $0.205^{\mathrm{a}}$ & 0.172 & 7.6 & 17.8 \\
\hline 24 & 0 & 217 & $0.934^{\mathrm{a}}$ & 0.966 & 0.3 & 66.1 & $0.232^{\mathrm{a}}$ & 0.196 & 8.2 & 21.3 \\
\hline 36 & 0 & 205 & $0.982^{\mathrm{a}}$ & 1.098 & 2.9 & 65.7 & $0.316^{\mathrm{a}}$ & 0.245 & 12.4 & 31.2 \\
\hline 48 & 0 & 193 & $1.114^{\mathrm{a}}$ & 1.197 & 4.7 & 66.0 & $0.424^{\mathrm{a}}$ & 0.311 & 15.8 & 38.7 \\
\hline 60 & 0 & 181 & $1.054^{\mathrm{a}}$ & 1.103 & 3.5 & 69.8 & $0.460^{\mathrm{a}}$ & 0.326 & 17.5 & 43.6 \\
\hline 1 & 1 & 60 & $1.105^{\mathrm{a}}$ & 1.074 & 0.0 & 96.8 & $0.105^{\mathrm{a}}$ & 0.046 & 8.4 & 10.7 \\
\hline 1 & 2 & 60 & $0.948^{\mathrm{a}}$ & 0.939 & 0.0 & 93.5 & 0.002 & 0.007 & 5.8 & 5.0 \\
\hline 1 & 3 & 60 & $1.020^{\mathrm{a}}$ & 1.063 & 0.0 & 97.2 & $0.156^{\mathrm{a}}$ & 0.082 & 4.2 & 12.9 \\
\hline 1 & 4 & 60 & $0.844^{\mathrm{a}}$ & 0.839 & 0.2 & 71.2 & $0.178^{\mathrm{a}}$ & 0.109 & 7.2 & 12.5 \\
\hline 3 & 1 & 58 & $1.172^{\mathrm{a}}$ & 1.185 & 0.0 & 87.1 & 0.004 & -0.041 & 7.1 & 6.5 \\
\hline 3 & 2 & 58 & $1.075^{\mathrm{a}}$ & 1.043 & 0.0 & 92.1 & $0.073^{\mathrm{a}}$ & 0.052 & 6.4 & 12.6 \\
\hline 3 & 3 & 58 & $1.042^{\mathrm{a}}$ & 1.063 & 0.0 & 95.9 & $0.223^{\mathrm{a}}$ & 0.110 & 6.9 & 18.7 \\
\hline 3 & 4 & 58 & $0.777^{\mathrm{a}}$ & 0.776 & 0.6 & 59.6 & $0.228^{\mathrm{a}}$ & 0.127 & 12.3 & 21.5 \\
\hline 6 & 1 & 55 & $1.064^{\mathrm{a}}$ & 1.060 & 0.5 & 72.5 & 0.021 & 0.030 & 11.2 & 13.0 \\
\hline 6 & 2 & 55 & $1.137^{\mathrm{a}}$ & 1.072 & 0.0 & 89.1 & $0.102^{\mathrm{a}}$ & 0.075 & 10.0 & 16.9 \\
\hline 6 & 3 & 55 & $0.988^{\mathrm{a}}$ & 0.981 & 0.0 & 84.2 & $0.349^{\mathrm{a}}$ & 0.212 & 6.0 & 23.5 \\
\hline 6 & 4 & 55 & $0.665^{\mathrm{a}}$ & 0.705 & 4.1 & 48.4 & $0.293^{\mathrm{a}}$ & 0.165 & 9.7 & 23.6 \\
\hline 9 & 1 & 52 & $0.924^{\mathrm{a}}$ & 0.860 & 0.9 & 61.9 & $-0.075^{\mathrm{b}}$ & 0.006 & 20.2 & 20.0 \\
\hline 9 & 2 & 52 & $1.197^{\mathrm{a}}$ & 1.088 & 0.1 & 86.4 & $0.146^{\mathrm{a}}$ & 0.095 & 12.9 & 22.3 \\
\hline 9 & 3 & 52 & $0.854^{\mathrm{a}}$ & 0.822 & 0.4 & 66.5 & $0.546^{\mathrm{a}}$ & 0.377 & 9.2 & 29.2 \\
\hline 9 & 4 & 52 & $0.603^{\mathrm{a}}$ & 0.679 & 6.2 & 47.1 & $0.346^{\mathrm{a}}$ & 0.254 & 14.1 & 28.3 \\
\hline 12 & 1 & 49 & $0.870^{\mathrm{a}}$ & 0.772 & 4.2 & 56.4 & $-0.141^{\mathrm{a}}$ & -0.023 & 23.7 & 20.7 \\
\hline 12 & 2 & 49 & $1.245^{\mathrm{a}}$ & 1.102 & 0.7 & 87.9 & $0.188^{\mathrm{a}}$ & 0.102 & 21.0 & 30.6 \\
\hline 12 & 3 & 49 & $0.859^{\mathrm{a}}$ & 0.809 & 8.6 & 65.4 & $0.522^{\mathrm{a}}$ & 0.399 & 12.9 & 34.0 \\
\hline 12 & 4 & 49 & $0.552^{\mathrm{a}}$ & 0.633 & 0.1 & 51.3 & $0.388^{\mathrm{a}}$ & 0.333 & 17.8 & 33.4 \\
\hline 15 & 1 & 46 & $0.817^{\mathrm{a}}$ & 0.681 & 1.9 & 50.9 & $-0.154^{\mathrm{a}}$ & -0.009 & 22.1 & 18.7 \\
\hline 15 & 2 & 46 & $1.289^{\mathrm{a}}$ & 1.136 & 1.9 & 87.4 & $0.228^{\mathrm{a}}$ & 0.133 & 29.2 & 39.1 \\
\hline 15 & 3 & 46 & $0.805^{\mathrm{a}}$ & 0.787 & 1.5 & 59.6 & $0.567^{\mathrm{a}}$ & 0.361 & 17.0 & 37.0 \\
\hline 15 & 4 & 46 & $0.493^{\mathrm{a}}$ & 0.601 & 13.2 & 51.3 & $0.404^{\mathrm{a}}$ & 0.334 & 19.7 & 38.1 \\
\hline 18 & 1 & 43 & $0.764^{\mathrm{a}}$ & 0.608 & 0.3 & 38.2 & $-0.169^{a}$ & -0.013 & 20.8 & 15.3 \\
\hline 18 & 2 & 43 & $1.330^{\mathrm{a}}$ & 1.180 & 1.8 & 85.8 & $0.259^{\mathrm{a}}$ & 0.148 & 30.2 & 41.4 \\
\hline 18 & 3 & 43 & $0.729^{\mathrm{a}}$ & 0.711 & 4.8 & 59.2 & $0.715^{\mathrm{a}}$ & 0.485 & 21.7 & 41.1 \\
\hline 18 & 4 & 43 & $0.436^{\mathrm{a}}$ & 0.568 & 17.2 & 52.3 & $0.432^{\mathrm{a}}$ & 0.346 & 22.3 & 41.3 \\
\hline
\end{tabular}


Table III

Comparing the Distributions of Residual Equity Return Exchange Rate Exposure Estimates with Value and Equal Weighted Market Portfolios (N=910)

The table compares the distributions of the exchange rate exposures, estimated using the value-weighted (VW) and equal-weighted (EW) market indexes, respectively, to control for market-wide effect. The percents of significantly negative and positive estimates are based on a two-sided t-test at the $10 \%$ significant level, with the degree of freedom equals to the number of non-overlapping observations. Period 0 covers 7701-9612. The four sub-periods (1-4) are 7701-8112, 8201-8612, 8701-9112, and 9201-9612.

Exposure with the VW Market

Exposure with the EW Market

\begin{tabular}{|c|c|c|c|c|c|c|c|c|c|}
\hline $\begin{array}{l}\text { Horizon } \\
\text { (months) }\end{array}$ & Period & Mean & Median & $\begin{array}{c}\text { Negative } \\
(\%)\end{array}$ & $\begin{array}{c}\text { Positive } \\
(\%)\end{array}$ & Mean & Median & $\begin{array}{c}\text { Negative } \\
(\%)\end{array}$ & $\begin{array}{c}\text { Positive } \\
(\%)\end{array}$ \\
\hline 1 & 0 & $0.104^{\mathrm{a}}$ & 0.071 & 6.7 & 15.8 & $-0.065^{\mathrm{a}}$ & -0.090 & 19.4 & 4.0 \\
\hline 3 & 0 & $0.132^{\mathrm{a}}$ & 0.076 & 8.6 & 22.6 & $-0.046^{\mathrm{a}}$ & -0.085 & 18.1 & 8.0 \\
\hline 6 & 0 & $0.157^{\mathrm{a}}$ & 0.104 & 5.9 & 18.4 & $-0.045^{\mathrm{a}}$ & -0.065 & 13.5 & 8.5 \\
\hline 9 & 0 & $0.139^{\mathrm{a}}$ & 0.105 & 6.7 & 16.8 & $-0.049^{\mathrm{a}}$ & -0.049 & 12.3 & 8.4 \\
\hline 12 & 0 & $0.143^{\mathrm{a}}$ & 0.116 & 7.3 & 16.2 & $-0.063^{\mathrm{a}}$ & -0.066 & 13.1 & 8.3 \\
\hline 15 & 0 & $0.167^{\mathrm{a}}$ & 0.127 & 7.2 & 17.4 & $-0.079^{\mathrm{a}}$ & -0.096 & 14.0 & 8.6 \\
\hline 18 & 0 & $0.183^{\mathrm{a}}$ & 0.149 & 6.9 & 17.0 & $-0.085^{\mathrm{a}}$ & -0.104 & 16.3 & 9.2 \\
\hline 21 & 0 & $0.205^{\mathrm{a}}$ & 0.172 & 7.6 & 17.8 & $-0.095^{\mathrm{a}}$ & -0.113 & 17.1 & 9.8 \\
\hline 24 & 0 & $0.232^{\mathrm{a}}$ & 0.196 & 8.2 & 21.3 & $-0.106^{\mathrm{a}}$ & -0.141 & 19.3 & 10.9 \\
\hline 36 & 0 & $0.316^{\mathrm{a}}$ & 0.245 & 12.4 & 31.2 & $-0.142^{\mathrm{a}}$ & -0.185 & 26.7 & 13.3 \\
\hline 48 & 0 & $0.424^{\mathrm{a}}$ & 0.311 & 15.8 & 38.7 & $-0.206^{\mathrm{a}}$ & -0.268 & 36.1 & 14.2 \\
\hline 60 & 0 & $0.460^{\mathrm{a}}$ & 0.326 & 17.5 & 43.6 & $-0.253^{\mathrm{a}}$ & -0.350 & 42.6 & 15.3 \\
\hline 1 & 1 & $0.105^{\mathrm{a}}$ & 0.046 & 8.4 & 10.7 & $-0.055^{\mathrm{a}}$ & -0.101 & 14.5 & 6.2 \\
\hline 1 & 2 & 0.002 & 0.007 & 5.8 & 5.0 & $-0.029^{b}$ & -0.023 & 7.1 & 4.5 \\
\hline 1 & 3 & $0.156^{\mathrm{a}}$ & 0.082 & 4.2 & 12.9 & $-0.105^{\mathrm{a}}$ & -0.143 & 14.3 & 3.4 \\
\hline 1 & 4 & $0.178^{\mathrm{a}}$ & 0.109 & 7.2 & 12.5 & $-0.049^{\mathrm{a}}$ & -0.056 & 10.7 & 4.5 \\
\hline 3 & 1 & 0.004 & -0.041 & 7.1 & 6.5 & 0.001 & -0.055 & 7.6 & 7.5 \\
\hline 3 & 2 & $0.073^{\mathrm{a}}$ & 0.052 & 6.4 & 12.6 & $-0.039^{b}$ & -0.053 & 10.8 & 8.2 \\
\hline 3 & 3 & $0.223^{\mathrm{a}}$ & 0.110 & 6.9 & 18.7 & $-0.060^{\mathrm{a}}$ & -0.134 & 16.0 & 5.8 \\
\hline 3 & 4 & $0.228^{\mathrm{a}}$ & 0.127 & 12.3 & 21.5 & $-0.046^{\mathrm{c}}$ & -0.091 & 19.3 & 10.1 \\
\hline 6 & 1 & 0.021 & 0.030 & 11.2 & 13.0 & $0.047^{\mathrm{c}}$ & 0.040 & 12.1 & 15.9 \\
\hline 6 & 2 & $0.102^{\mathrm{a}}$ & 0.075 & 10.0 & 16.9 & $-0.053^{b}$ & -0.071 & 15.4 & 10.9 \\
\hline 6 & 3 & $0.349^{\mathrm{a}}$ & 0.212 & 6.0 & 23.5 & $-0.039^{\mathrm{c}}$ & -0.111 & 12.3 & 7.8 \\
\hline 6 & 4 & $0.293^{\mathrm{a}}$ & 0.165 & 9.7 & 23.6 & $-0.072^{b}$ & -0.100 & 17.1 & 11.5 \\
\hline 9 & 1 & $-0.075^{\mathrm{b}}$ & 0.006 & 20.2 & 20.0 & $0.075^{\mathrm{b}}$ & 0.109 & 15.3 & 26.1 \\
\hline 9 & 2 & $0.146^{\mathrm{a}}$ & 0.095 & 12.9 & 22.3 & $-0.069^{\mathrm{a}}$ & -0.099 & 20.7 & 14.5 \\
\hline 9 & 3 & $0.546^{\mathrm{a}}$ & 0.377 & 9.2 & 29.2 & -0.036 & -0.126 & 15.6 & 9.6 \\
\hline 9 & 4 & $0.346^{\mathrm{a}}$ & 0.254 & 14.1 & 28.3 & $-0.131^{a}$ & -0.181 & 20.4 & 14.5 \\
\hline 12 & 1 & $-0.141^{\mathrm{a}}$ & -0.023 & 23.7 & 20.7 & $0.083^{\mathrm{b}}$ & 0.122 & 15.9 & 28.5 \\
\hline 12 & 2 & $0.188^{\mathrm{a}}$ & 0.102 & 21.0 & 30.6 & $-0.094^{\mathrm{a}}$ & -0.161 & 35.1 & 20.5 \\
\hline 12 & 3 & $0.522^{\mathrm{a}}$ & 0.399 & 12.9 & 34.0 & 0.037 & -0.009 & 17.2 & 17.0 \\
\hline 12 & 4 & $0.388^{\mathrm{a}}$ & 0.333 & 17.8 & 33.4 & $-0.210^{\mathrm{a}}$ & -0.336 & 28.9 & 17.3 \\
\hline 15 & 1 & $-0.154^{\mathrm{a}}$ & -0.009 & 22.1 & 18.7 & $0.094^{\mathrm{b}}$ & 0.172 & 15.0 & 26.4 \\
\hline 15 & 2 & $0.228^{\mathrm{a}}$ & 0.133 & 29.2 & 39.1 & $-0.108^{\mathrm{a}}$ & -0.177 & 43.1 & 25.9 \\
\hline 15 & 3 & $0.567^{\mathrm{a}}$ & 0.361 & 17.0 & 37.0 & 0.067 & -0.081 & 19.1 & 20.1 \\
\hline 15 & 4 & $0.404^{\mathrm{a}}$ & 0.334 & 19.7 & 38.1 & $-0.206^{\mathrm{a}}$ & -0.356 & 31.4 & 16.1 \\
\hline 18 & 1 & $-0.169^{\mathrm{a}}$ & -0.013 & 20.8 & 15.3 & $0.104^{\mathrm{b}}$ & 0.181 & 15.2 & 26.0 \\
\hline 18 & 2 & $0.259^{\mathrm{a}}$ & 0.148 & 30.2 & 41.4 & $-0.112^{\mathrm{a}}$ & -0.182 & 44.8 & 27.2 \\
\hline 18 & 3 & $0.715^{\mathrm{a}}$ & 0.485 & 21.7 & 41.1 & 0.106 & -0.129 & 27.1 & 24.0 \\
\hline 18 & 4 & $0.432^{\mathrm{a}}$ & 0.346 & 22.3 & 41.3 & $-0.179^{b}$ & -0.410 & 38.0 & 21.3 \\
\hline
\end{tabular}

$\mathrm{a}, \mathrm{b}$, and c denote statistically significant at the $1 \%, 5 \%$, and $10 \%$ level, respectively, using a two-tailed $t$-test. 
Table IV

Descriptive Statistics on CRSP Market Exchange Rate Exposure

The table reports the exposure estimates of the value-weighted (VW) and equal-weighted (EW) portfolios.

Currency exposures are estimated using monthly overlapping observations. Period 0 covers 7701-9612. The four sub-periods (1-4) are 7701-8112, 8201-8612, 8701-9112, and 9201-9612.

\begin{tabular}{|c|c|c|c|c|c|c|c|c|c|}
\hline \multirow[b]{2}{*}{$\begin{array}{l}\text { Horizon } \\
\text { (months) }\end{array}$} & \multirow[b]{2}{*}{ Period } & \multirow[b]{2}{*}{$\mathrm{T}$} & \multicolumn{2}{|c|}{ VW Market } & \multicolumn{2}{|c|}{ EW Market } & VW & versus & EW \\
\hline & & & $\begin{array}{l}\text { Currency } \\
\text { exposure }\end{array}$ & t-ratio & $\begin{array}{l}\text { Currency } \\
\text { exposure }\end{array}$ & t-ratio & Diff. & t-ratio & Test* \\
\hline 1 & 0 & 240 & 0.028 & 0.215 & 0.219 & 1.299 & -0.191 & -0.894 & \\
\hline 3 & 0 & 238 & 0.116 & 0.702 & 0.342 & 1.723 & -0.226 & -0.873 & \\
\hline 6 & 0 & 235 & 0.080 & 0.459 & 0.327 & 1.612 & -0.247 & -0.921 & \\
\hline 9 & 0 & 232 & -0.032 & -0.165 & 0.179 & 0.828 & -0.210 & -0.729 & \\
\hline 12 & 0 & 229 & -0.113 & -0.555 & 0.109 & 0.466 & -0.222 & -0.716 & \\
\hline 15 & 0 & 226 & -0.181 & -0.848 & 0.082 & 0.335 & -0.263 & -0.810 & \\
\hline 18 & 0 & 223 & -0.242 & -1.187 & 0.042 & 0.185 & -0.283 & -0.932 & \\
\hline 21 & 0 & 220 & -0.303 & -1.647 & 0.014 & 0.072 & -0.317 & -1.187 & \\
\hline 24 & 0 & 217 & -0.303 & -1.774 & 0.066 & 0.362 & -0.368 & -1.477 & \\
\hline 36 & 0 & 205 & -0.223 & -1.885 & 0.278 & 1.929 & -0.501 & -2.687 & $\mathrm{a}$ \\
\hline 48 & 0 & 193 & -0.307 & -4.134 & 0.322 & 2.940 & -0.629 & -4.753 & $\mathrm{a}$ \\
\hline 60 & 0 & 181 & -0.260 & -3.287 & 0.455 & 3.533 & -0.715 & -4.730 & $\mathrm{a}$ \\
\hline 1 & 1 & 60 & -0.187 & -0.569 & -0.053 & -0.104 & -0.134 & -0.221 & \\
\hline 1 & 2 & 60 & -0.017 & -0.104 & 0.017 & 0.091 & -0.035 & -0.137 & \\
\hline 1 & 3 & 60 & 0.227 & 0.816 & 0.523 & 1.779 & -0.296 & -0.730 & \\
\hline 1 & 4 & 60 & 0.099 & 0.785 & 0.387 & 2.173 & -0.288 & -1.318 & \\
\hline 3 & 1 & 58 & -0.144 & -0.683 & -0.186 & -0.631 & 0.042 & 0.116 & \\
\hline 3 & 2 & 58 & -0.246 & -1.085 & -0.175 & -0.654 & -0.071 & -0.203 & \\
\hline 3 & 3 & 58 & 0.854 & 2.436 & 1.305 & 3.295 & -0.451 & -0.852 & \\
\hline 3 & 4 & 58 & 0.115 & 0.928 & 0.446 & 3.286 & -0.330 & -1.794 & $c$ \\
\hline 6 & 1 & 55 & -0.075 & -0.354 & -0.121 & -0.530 & 0.045 & 0.146 & \\
\hline 6 & 2 & 55 & -0.293 & -1.528 & -0.205 & -0.882 & -0.088 & -0.292 & \\
\hline 6 & 3 & 55 & 0.992 & 3.740 & 1.549 & 4.909 & -0.557 & -1.350 & \\
\hline 6 & 4 & 55 & 0.229 & 1.194 & 0.632 & 3.643 & -0.403 & -1.559 & \\
\hline 9 & 1 & 52 & -0.074 & -0.333 & -0.248 & -1.109 & 0.174 & 0.551 & \\
\hline 9 & 2 & 52 & -0.294 & -1.860 & -0.162 & -0.696 & -0.132 & -0.470 & \\
\hline 9 & 3 & 52 & 1.198 & 6.104 & 1.803 & 9.625 & -0.605 & -2.230 & $\mathrm{~b}$ \\
\hline 9 & 4 & 52 & 0.301 & 1.109 & 0.764 & 3.691 & -0.463 & -1.359 & \\
\hline 12 & 1 & 49 & 0.072 & 0.347 & -0.185 & -1.017 & 0.257 & 0.932 & \\
\hline 12 & 2 & 49 & -0.324 & -1.720 & -0.145 & -0.464 & -0.179 & -0.491 & \\
\hline 12 & 3 & 49 & 1.041 & 9.343 & 1.584 & 6.238 & -0.542 & -1.957 & $\mathrm{c}$ \\
\hline 12 & 4 & 49 & 0.233 & 0.920 & 0.800 & 4.530 & -0.566 & -1.832 & $\mathrm{c}$ \\
\hline 15 & 1 & 46 & 0.206 & 1.360 & -0.091 & -0.742 & 0.297 & 1.523 & \\
\hline 15 & 2 & 46 & -0.350 & -1.830 & -0.140 & -0.424 & -0.210 & -0.550 & \\
\hline 15 & 3 & 46 & 0.903 & 12.271 & 1.398 & 6.614 & -0.495 & -2.211 & $\mathrm{~b}$ \\
\hline 15 & 4 & 46 & 0.232 & 1.183 & 0.806 & 7.814 & -0.574 & -2.591 & a \\
\hline 18 & 1 & 43 & 0.244 & 2.063 & -0.097 & -1.496 & 0.342 & 2.528 & $\mathrm{~b}$ \\
\hline 18 & 2 & 43 & -0.352 & -2.008 & -0.119 & -0.399 & -0.233 & -0.673 & \\
\hline 18 & 3 & 43 & 0.804 & 5.659 & 1.374 & 12.135 & -0.569 & -3.132 & $\mathrm{a}$ \\
\hline 18 & 4 & 43 & 0.169 & 0.818 & 0.771 & 11.194 & -0.602 & -2.769 & $\mathrm{a}$ \\
\hline
\end{tabular}

a, b, and c denote statistically significantly different at the 1\%,5\%, and 10\% level, respectively, using a two sample $t$-test (2sided). 
Table V

Descriptive Statistics on CRSP Cap-Based Portfolios Exchange Rate Exposure

The table reports the exposure estimates of the CRSP cap based size 1 (largest), size 4, size 7, and size 10 (smallest) portfolios. Currency exposures are estimated using monthly overlapping observations. Period 0 covers 7701-9612. The four sub-periods (1-4) are 7701-8112, 8201-8612, 8701-9112, and 9201-9612.

\begin{tabular}{|c|c|c|c|c|c|c|c|c|c|c|c|c|c|}
\hline \multirow[b]{2}{*}{$\begin{array}{l}\text { Horizon } \\
\text { (months) }\end{array}$} & \multirow[b]{2}{*}{ Period } & \multirow[b]{2}{*}{$\mathrm{T}$} & \multicolumn{2}{|c|}{ Size 1} & \multicolumn{3}{|c|}{ Size 4} & \multicolumn{3}{|c|}{ Size 7} & \multicolumn{3}{|c|}{ Size 10} \\
\hline & & & $\begin{array}{l}\text { Currency } \\
\text { exposure }\end{array}$ & t-ratio & $\begin{array}{l}\text { Currency } \\
\text { exposure }\end{array}$ & t-ratio I & Diff. ${ }^{*}$ & $\begin{array}{l}\text { Currency } \\
\text { exposure }\end{array}$ & t-ratio & Diff. & $\begin{array}{l}\text { Currency } \\
\text { exposure }\end{array}$ & t-ratio I & Diff." \\
\hline 1 & 0 & 240 & -0.004 & -0.032 & 0.082 & 0.535 & & 0.210 & 1.138 & & 0.408 & 2.010 & $\mathrm{~b}$ \\
\hline 3 & 0 & 238 & 0.065 & 0.403 & 0.206 & 1.174 & & 0.341 & 1.606 & & 0.574 & 2.460 & $\mathrm{~b}$ \\
\hline 6 & 0 & 235 & 0.003 & 0.018 & 0.188 & 1.058 & & 0.351 & 1.664 & $\mathrm{c}$ & 0.535 & 2.164 & $\mathrm{~b}$ \\
\hline 9 & 0 & 232 & -0.107 & -0.545 & 0.067 & 0.331 & & 0.225 & 0.988 & & 0.332 & 1.254 & \\
\hline 12 & 0 & 229 & -0.189 & -0.916 & -0.017 & -0.075 & & 0.156 & 0.630 & & 0.281 & 0.970 & \\
\hline 15 & 0 & 226 & -0.261 & -1.214 & -0.087 & -0.374 & & 0.114 & 0.449 & & 0.296 & 0.982 & \\
\hline 18 & 0 & 223 & -0.324 & -1.559 & -0.149 & -0.684 & & 0.068 & 0.290 & & 0.274 & 0.990 & \\
\hline 21 & 0 & 220 & -0.394 & -2.052 & -0.203 & -1.056 & & 0.033 & 0.169 & & 0.271 & 1.161 & \\
\hline 24 & 0 & 217 & -0.405 & -2.257 & -0.184 & -1.013 & & 0.081 & 0.484 & & 0.360 & 1.670 & $\mathrm{c}$ \\
\hline 36 & 0 & 205 & -0.344 & -2.725 & -0.072 & -0.482 & & 0.280 & 2.429 & $\mathrm{c}$ & 0.685 & 3.799 & $\mathrm{a}$ \\
\hline 48 & 0 & 193 & -0.455 & -5.496 & -0.127 & -1.297 & & 0.302 & 3.044 & & 0.837 & 5.045 & $\mathrm{a}$ \\
\hline 60 & 0 & 181 & -0.438 & -5.142 & -0.049 & -0.541 & & 0.417 & 3.568 & $\mathrm{c}$ & 1.040 & 5.054 & $\mathrm{a}$ \\
\hline 1 & 1 & 60 & -0.189 & -0.697 & -0.181 & -0.417 & & -0.078 & -0.140 & & 0.067 & 0.107 & \\
\hline 1 & 2 & 60 & -0.004 & -0.026 & -0.060 & -0.325 & & -0.016 & -0.076 & & 0.093 & 0.449 & \\
\hline 1 & 3 & 60 & 0.158 & 0.576 & 0.335 & 1.111 & & 0.584 & 1.775 & & 0.787 & 2.467 & $\mathrm{c}$ \\
\hline 1 & 4 & 60 & 0.030 & 0.218 & 0.265 & 1.890 & & 0.322 & 1.917 & $\mathrm{c}$ & 0.668 & 2.200 & b \\
\hline 3 & 1 & 58 & -0.124 & -0.644 & -0.207 & -0.731 & & -0.293 & -0.853 & & -0.140 & -0.401 & \\
\hline 3 & 2 & 58 & -0.254 & -1.188 & -0.249 & -1.052 & & -0.151 & -0.576 & & -0.133 & -0.437 & \\
\hline 3 & 3 & 58 & 0.750 & 2.139 & 1.022 & 2.932 & & 1.380 & 3.288 & & 1.708 & 3.812 & \\
\hline 3 & 4 & 58 & 0.033 & 0.253 & 0.362 & 2.478 & $\mathrm{~b}$ & 0.413 & 2.883 & $\mathrm{a}$ & 0.825 & 3.824 & $\mathrm{a}$ \\
\hline 6 & 1 & 55 & -0.120 & -0.507 & -0.036 & -0.175 & & -0.196 & -0.759 & & -0.112 & -0.388 & \\
\hline 6 & 2 & 55 & -0.303 & -1.637 & -0.315 & -1.608 & & -0.193 & -0.885 & & -0.162 & -0.580 & \\
\hline 6 & 3 & 55 & 0.854 & 3.058 & 1.202 & 4.819 & & 1.646 & 5.654 & & 2.012 & 5.552 & \\
\hline 6 & 4 & 55 & 0.103 & 0.491 & 0.536 & 2.822 & $\mathrm{~b}$ & 0.660 & 3.160 & $\mathrm{~b}$ & 0.966 & 3.605 & $\mathrm{a}$ \\
\hline 9 & 1 & 52 & -0.105 & -0.436 & -0.030 & -0.152 & & -0.306 & -1.238 & & -0.340 & -1.124 & \\
\hline 9 & 2 & 52 & -0.310 & -2.151 & -0.323 & -1.541 & & -0.143 & -0.652 & & -0.087 & -0.285 & \\
\hline 9 & 3 & 52 & 1.015 & 4.282 & 1.469 & 11.471 & & 1.931 & 11.069 & & 2.244 & 11.052 & \\
\hline 9 & 4 & 52 & 0.128 & 0.405 & 0.673 & 3.046 & $\mathrm{~b}$ & 0.750 & 3.115 & $\mathrm{~b}$ & 0.901 & 2.862 & $\mathrm{~b}$ \\
\hline 12 & 1 & 49 & 0.065 & 0.285 & 0.083 & 0.479 & & -0.209 & -0.991 & & -0.333 & -1.294 & \\
\hline 12 & 2 & 49 & -0.340 & -2.196 & -0.370 & -1.329 & & -0.127 & -0.412 & & -0.024 & -0.059 & \\
\hline 12 & 3 & 49 & 0.851 & 6.878 & 1.307 & 5.917 & & 1.732 & 8.917 & & 1.994 & 6.069 & \\
\hline 12 & 4 & 49 & 0.028 & 0.093 & 0.672 & 3.291 & $\mathrm{a}$ & 0.756 & 3.518 & $\mathrm{a}$ & 0.975 & 4.148 & $\mathrm{a}$ \\
\hline 15 & 1 & 46 & 0.201 & 1.156 & 0.207 & 1.879 & & -0.071 & -0.485 & & -0.284 & -1.313 & $\mathrm{c}$ \\
\hline 15 & 2 & 46 & -0.364 & -2.412 & -0.406 & -1.400 & & -0.121 & -0.364 & & 0.018 & 0.041 & \\
\hline 15 & 3 & 46 & 0.721 & 8.248 & 1.190 & 6.514 & & 1.539 & 8.184 & & 1.847 & 5.796 & \\
\hline 15 & 4 & 46 & 0.027 & 0.107 & 0.651 & 5.195 & $\mathrm{a}$ & 0.758 & 6.203 & $\mathrm{a}$ & 0.980 & 4.980 & $\mathrm{a}$ \\
\hline 18 & 1 & 43 & 0.249 & 1.784 & 0.232 & 3.134 & & -0.060 & -0.881 & & -0.337 & -2.015 & $c$ \\
\hline 18 & 2 & 43 & -0.365 & -2.637 & -0.414 & -1.593 & & -0.098 & -0.323 & & 0.068 & 0.175 & \\
\hline 18 & 3 & 43 & 0.581 & 3.429 & 1.202 & 12.444 & & 1.571 & 13.575 & $c$ & 1.946 & 14.206 & $\mathrm{~b}$ \\
\hline 18 & 4 & 43 & -0.062 & -0.223 & 0.624 & 6.159 & $\mathrm{a}$ & 0.716 & 7.337 & $\mathrm{a}$ & 0.945 & 6.680 & $\mathrm{a}$ \\
\hline
\end{tabular}

* a, b, and c denote statistically significantly different from the exposure estimate of the size 1 portfolio at the $1 \%$, $5 \%$, and $10 \%$ level, respectively, using a two sample $t$-test (2-sided). 
Table VI

\section{Descriptive Statistics on the Self-Constructed Portfolio by Size and Foreign Sales Percentage}

The time-series means (1979-1996) of the selected portfolio characteristics are reported in the table. The portfolios are constructed as follows. (1) Firms are selected if they have non-missing data in the Compustat industry annual or full coverage files, the Compustat geographic segment files, and CRSP monthly stock file. (2) For each sample year, the selected firms are divided into ten deciles according to their market capitalization in the beginning of the year. (3) For each sample year and size decile, we further divided the firms into three sub-portfolios: high, low, and zero foreign-and-export sales. We compute foreign-and-export sales (\%FGN Sales) as the sum of foreign sales and export sales, scaled by total firm sales.

\begin{tabular}{llrrrr} 
\%FGN Sales & Mean & Size 1 & Size 4 & Size 7 & Size 10 \\
\hline \multirow{3}{*}{ High } & & & & & \\
& MV & $557,862,546$ & $15,420,159$ & $2,658,751$ & 193,030 \\
& N & 49.2 & 32.8 & 29.4 & 21.7 \\
& MV / N & $10,717,066$ & 439,583 & 82,317 & 8,441 \\
& \%FGN Sales & $50 \%$ & $34 \%$ & $31 \%$ & $31 \%$ \\
Low & & & & \\
& MV & $399,160,539$ & $15,256,485$ & $2,639,744$ & 173,016 \\
& N & 49.8 & 33.2 & 29.7 & 21.9 \\
& MV / N & $7,479,602$ & 429,588 & 81,240 & 7,513 \\
& \%FGN Sales & $15 \%$ & $5 \%$ & $3 \%$ & $0 \%$ \\
\multirow{2}{*}{ Zero } & & & & \\
& MV & $401,108,522$ & $39,130,370$ & $8,106,513$ & 832,778 \\
& N & 50.2 & 83.2 & 90.2 & 104.1 \\
& MV / N & $7,052,258$ & 434,620 & 83,551 & 7,662 \\
& \%FGN Sales & $0 \%$ & $0 \%$ & $0 \%$ & $0 \%$ \\
& & & & & \\
\hline
\end{tabular}

\footnotetext{
$\%$ FGN Sales = Value-weighted average of foreign-and-exports sales as a percentage of total firm sales MV $\quad=$ Market capitalization in the beginning of year

$\mathrm{N} \quad=$ Number of firms in the size portfolio

$\mathrm{MV} / \mathrm{N}=$ Market capitalization of the average firm in the size portfolio
} 
Table VII

Descriptive Statistics on Exchange Rate Exposure of Cap-Based Portfolios by the Extent of Foreign Operations

The portfolios are constructed as follows. (1) Firms are selected if they have non-missing data in the Compustat industry annual or full coverage files, the Compustat geographic segment files, and CRSP monthly stock file. (2) For each sample year, the selected firms are divided into ten deciles according to their market capitalization in the beginning of the year. (3) For each sample year and size decile, we further divided the firms into three subportfolios: high, low, and zero foreign-and-export sales. We compute foreign-and-export sales (\%FGN Sales) as the sum of foreign sales and export sales, scaled by total firm sales.

\begin{tabular}{|c|c|c|c|c|c|c|c|c|c|c|c|c|}
\hline \multirow[b]{2}{*}{$\begin{array}{c}\% \text { FGN } \\
\text { Sales }\end{array}$} & \multirow[b]{2}{*}{$\begin{array}{c}\text { Horizon } \\
\text { (months) }\end{array}$} & \multicolumn{2}{|c|}{ Size 1} & \multicolumn{3}{|c|}{ Size 4} & \multicolumn{3}{|c|}{ Size 7} & \multicolumn{3}{|c|}{ Size 10} \\
\hline & & $\begin{array}{l}\text { Currency } \\
\text { exposure }\end{array}$ & std err & $\begin{array}{l}\text { Currency } \\
\text { exposure }\end{array}$ & std err & Diff. $^{*}$ & $\begin{array}{l}\text { Currency } \\
\text { exposure }\end{array}$ & std err & Diff." $^{*}$ & $\begin{array}{l}\text { Currency } \\
\text { exposure }\end{array}$ & std err & Dif \\
\hline High & 1 & -0.092 & 0.106 & 0.062 & 0.155 & & 0.111 & 0.182 & & 0.340 & 0.208 & \\
\hline & 3 & -0.005 & 0.158 & 0.305 & 0.209 & & 0.416 & 0.241 & & 0.553 & 0.242 & \\
\hline & 6 & -0.072 & 0.166 & 0.321 & 0.218 & & 0.409 & 0.244 & c & 0.465 & 0.224 & \\
\hline & 9 & -0.180 & 0.166 & 0.183 & 0.238 & & 0.313 & 0.265 & & 0.385 & 0.238 & \\
\hline & 12 & -0.268 & 0.167 & 0.085 & 0.255 & & 0.272 & 0.291 & & 0.333 & 0.268 & \\
\hline & 15 & -0.309 & 0.174 & 0.045 & 0.270 & & 0.258 & 0.314 & & 0.291 & 0.296 & \\
\hline & 18 & -0.342 & 0.171 & 0.014 & 0.254 & & 0.235 & 0.301 & & 0.217 & 0.301 & \\
\hline & 21 & -0.395 & 0.159 & -0.024 & 0.224 & & 0.227 & 0.284 & & 0.133 & 0.288 & \\
\hline & 24 & -0.392 & 0.154 & 0.012 & 0.207 & & 0.285 & 0.272 & c & 0.127 & 0.273 & 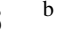 \\
\hline & 36 & -0.266 & 0.122 & 0.274 & 0.168 & & 0.509 & 0.226 & a & 0.326 & 0.186 & 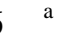 \\
\hline & 48 & -0.323 & 0.084 & 0.319 & 0.135 & & 0.576 & 0.240 & a & 0.366 & 0.206 & $a^{a}$ \\
\hline & 60 & -0.316 & 0.072 & 0.408 & 0.119 & & 0.766 & 0.233 & $\mathrm{a}$ & 0.556 & 0.234 & ${ }^{a}$ \\
\hline Low & 1 & 0.033 & 0.124 & 0.082 & 0.159 & & 0.240 & 0.183 & & 0.477 & 0.226 & \\
\hline & 3 & 0.178 & 0.177 & 0.392 & 0.210 & & 0.633 & 0.232 & & 0.582 & 0.300 & ) \\
\hline & 6 & 0.156 & 0.189 & 0.381 & 0.231 & & 0.670 & 0.244 & & 0.485 & 0.319 & \\
\hline & 9 & 0.072 & 0.199 & 0.255 & 0.246 & & 0.517 & 0.275 & & 0.336 & 0.363 & \\
\hline & 12 & 0.003 & 0.207 & 0.130 & 0.260 & & 0.451 & 0.311 & & 0.351 & 0.411 & \\
\hline & 15 & -0.050 & 0.220 & 0.049 & 0.275 & & 0.449 & 0.332 & & 0.415 & 0.443 & 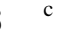 \\
\hline & 18 & -0.100 & 0.215 & -0.027 & 0.256 & & 0.423 & 0.314 & c & 0.438 & 0.422 & \\
\hline & 21 & -0.165 & 0.192 & -0.120 & 0.214 & & 0.404 & 0.293 & c & 0.490 & 0.385 & \\
\hline & 24 & -0.160 & 0.175 & -0.110 & 0.198 & & 0.486 & 0.283 & b & 0.649 & 0.359 & 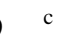 \\
\hline & 36 & -0.077 & 0.099 & 0.034 & 0.159 & $\mathrm{a}$ & 0.847 & 0.272 & $\mathrm{a}$ & 1.241 & 0.252 & 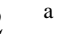 \\
\hline & 48 & -0.156 & 0.069 & -0.028 & 0.115 & a & 1.006 & 0.250 & a & 1.424 & 0.199 & 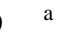 \\
\hline & 60 & -0.087 & 0.091 & 0.024 & 0.110 & ${ }^{a}$ & 1.181 & 0.205 & $\mathrm{a}$ & 1.526 & 0.246 & a \\
\hline Zero & 1 & 0.018 & 0.099 & 0.043 & 0.118 & & 0.123 & 0.135 & & 0.363 & 0.176 & \\
\hline & 3 & 0.076 & 0.132 & 0.306 & 0.162 & & 0.430 & 0.182 & & 0.750 & 0.236 & \\
\hline & 6 & 0.071 & 0.143 & 0.416 & 0.172 & & 0.549 & 0.186 & b & 0.738 & 0.257 & \\
\hline & 9 & 0.024 & 0.173 & 0.382 & 0.213 & & 0.526 & 0.223 & c & 0.599 & 0.287 & \\
\hline & 12 & -0.050 & 0.187 & 0.332 & 0.249 & & 0.500 & 0.258 & c & 0.594 & 0.326 & \\
\hline & 15 & -0.107 & 0.192 & 0.290 & 0.264 & & 0.501 & 0.273 & c & 0.616 & 0.356 & \\
\hline & 18 & -0.159 & 0.189 & 0.252 & 0.264 & & 0.493 & 0.264 & b & 0.596 & 0.340 & \\
\hline & 21 & -0.225 & 0.173 & 0.211 & 0.256 & & 0.485 & 0.248 & b & 0.575 & 0.308 & \\
\hline & 24 & -0.242 & 0.157 & 0.235 & 0.260 & & 0.536 & 0.241 & a & 0.646 & 0.299 & \\
\hline & 36 & -0.234 & 0.093 & 0.364 & 0.228 & b & 0.804 & 0.219 & a & 0.939 & 0.230 & $a^{a}$ \\
\hline & 48 & -0.351 & 0.070 & 0.329 & 0.147 & a & 0.915 & 0.198 & a & 0.942 & 0.137 & 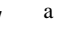 \\
\hline & 60 & -0.329 & 0.087 & 0.416 & 0.104 & ${ }^{a}$ & 1.096 & 0.178 & a & 1.069 & 0.161 & \\
\hline
\end{tabular}

\footnotetext{
a, b, and c denote statistically significantly different from the exposure estimate of the size 1 portfolio at the $1 \%, 5 \%$, and $10 \%$ level, respectively, using a two sample $t$-test (1-sided).
} 
Table VIII

Regressions of Exchange Rate Exposure Estimates on Foreign-And-Export Sales and Size Residual Currency Exposure Estimates (VW market portfolio control)

Currency exposures are estimated using monthly overlapping observations over the period 7701-9612. We measure foreign-and-export sales (\%FGN Sales) and size (MVE) using, respectively, the mean annual foreign-and-export sales and mean market value of equity over the period 7701-9612.

\begin{tabular}{|c|c|c|c|c|}
\hline Horizon & Constant & $\%$ FGN Sales & MVE & Adj. $R^{2}$ \\
\hline 01 & $\begin{array}{c}0.136 \\
(11.677)^{* * * *}\end{array}$ & $\begin{array}{l}-0.215 \\
(-3.167)^{* * *}\end{array}$ & $\begin{array}{l}-0.008 \\
(-4.372)^{* * *}\end{array}$ & 0.050 \\
\hline 03 & $\begin{array}{c}0.172 \\
(11.378)^{* * * *}\end{array}$ & $\begin{array}{l}-0.281 \\
(-3.187) * * *\end{array}$ & $\begin{array}{l}-0.009 \\
(-3.771) * * *\end{array}$ & 0.042 \\
\hline 06 & $\begin{array}{c}0.213 \\
(12.275)^{* * * *}\end{array}$ & $\begin{array}{l}-0.454 \\
(-4.489) * * *\end{array}$ & $\begin{array}{l}-0.009 \\
(-3.442)^{* * *}\end{array}$ & 0.055 \\
\hline 09 & $\begin{array}{c}0.204 \\
(10.266)^{* * * *}\end{array}$ & $\begin{array}{l}-0.609 \\
(-5.247) * * *\end{array}$ & $\begin{array}{l}-0.008 \\
(-2.432)^{* *}\end{array}$ & 0.054 \\
\hline 12 & $\begin{array}{c}0.219 \\
(10.006)^{* * * *}\end{array}$ & $\begin{array}{l}-0.722 \\
(-5.643) * * *\end{array}$ & $\begin{array}{l}-0.008 \\
(-2.351)^{* *}\end{array}$ & 0.060 \\
\hline 15 & $\begin{array}{c}0.25 \\
(10.690)^{* * *}\end{array}$ & $\begin{array}{l}-0.775 \\
(-5.670) * * *\end{array}$ & $\begin{array}{l}-0.009 \\
(-2.546)^{* *}\end{array}$ & 0.062 \\
\hline 18 & $\begin{array}{c}0.269 \\
(10.675)^{* * * *}\end{array}$ & $\begin{array}{l}-0.839 \\
(-5.697)^{* * *}\end{array}$ & $\begin{array}{l}-0.009 \\
(-2.343)^{* *}\end{array}$ & 0.061 \\
\hline 21 & $\begin{array}{c}0.299 \\
(10.662)^{* * * *}\end{array}$ & $\begin{array}{l}-0.955 \\
(-5.826)^{* * *}\end{array}$ & $\begin{array}{l}-0.009 \\
(-2.112)^{* *}\end{array}$ & 0.060 \\
\hline 24 & $\begin{array}{c}0.335 \\
(10.975)^{* * *}\end{array}$ & $\begin{array}{l}-1.07 \\
(-6.010)^{* * *}\end{array}$ & $\begin{array}{c}-0.009 \\
(-1.943)^{*}\end{array}$ & 0.061 \\
\hline 36 & $\begin{array}{c}0.431 \\
(12.124)^{* * * *}\end{array}$ & $\begin{array}{l}-1.198 \\
(-5.764) * * *\end{array}$ & $\begin{array}{l}-0.011 \\
(-1.997)^{* *}\end{array}$ & 0.058 \\
\hline 48 & $\begin{array}{c}0.556 \\
(12.220)^{* * * *}\end{array}$ & $\begin{array}{l}-1.447 \\
(-5.446)^{* * *}\end{array}$ & $\begin{array}{l}-0.015 \\
(-2.042)^{* *}\end{array}$ & 0.053 \\
\hline 60 & $\begin{array}{l}0.6 \\
(12.936)^{* * *}\end{array}$ & $\begin{array}{l}-1.401 \\
(-5.174)^{* * *}\end{array}$ & $\begin{array}{l}-0.02 \\
(-2.714)^{* * *}\end{array}$ & 0.056 \\
\hline
\end{tabular}

$*$, **, and $* * *$ denote statistically significant at the $1 \%, 5 \%$, and $10 \%$ level, respectively, using a two-tailed $t$-test. 
Table IX

Descriptive Statistics on Equity Return Residual Exchange Rate Exposure Estimates with Matching CRSP Cap-Based Portfolio ( $=910)$

Currency exposures are estimated using monthly overlapping observations, with the number of overlapping observations reported under the column titled "T." The percents of significantly negative and positive estimates are based on a two-sided t-test at the $10 \%$ significant level, with the degree of freedom equals to the number of nonoverlapping observations. Period 0 covers 7701-9612. The four sub-periods (1-4) are 7701-8112, 8201-8612, 87019112, and 9201-9612.

\begin{tabular}{|c|c|c|c|c|c|c|c|c|c|c|}
\hline \multirow[b]{2}{*}{$\begin{array}{l}\text { Horizon } \\
\text { (months) }\end{array}$} & \multirow[b]{2}{*}{ Period } & \multirow[b]{2}{*}{$\mathrm{T}$} & \multicolumn{4}{|c|}{ Matching CRSP Cap-Based "Beta" } & \multicolumn{4}{|c|}{ Currency exposure } \\
\hline & & & Mean & Median & $\begin{array}{c}\text { Negative } \\
(\%)\end{array}$ & $\begin{array}{c}\text { Positive } \\
(\%)\end{array}$ & Mean & Median & $\begin{array}{c}\text { Negative } \\
(\%)\end{array}$ & $\begin{array}{c}\text { Positive } \\
(\%)\end{array}$ \\
\hline 1 & 0 & 240 & $0.758^{\mathrm{a}}$ & 0.748 & 0.0 & 99.5 & $-0.082^{\mathrm{a}}$ & -0.121 & 25.3 & 4.8 \\
\hline 3 & 0 & 238 & $0.757^{\mathrm{a}}$ & 0.748 & 0.0 & 96.9 & $-0.088^{\mathrm{a}}$ & -0.127 & 24.2 & 6.8 \\
\hline 6 & 0 & 235 & $0.752^{\mathrm{a}}$ & 0.725 & 0.0 & 92.7 & $-0.102^{\mathrm{a}}$ & -0.103 & 17.0 & 6.3 \\
\hline 9 & 0 & 232 & $0.746^{\mathrm{a}}$ & 0.703 & 0.0 & 89.7 & $-0.125^{\mathrm{a}}$ & -0.112 & 15.8 & 5.3 \\
\hline 12 & 0 & 229 & $0.729^{\mathrm{a}}$ & 0.666 & 0.0 & 81.0 & $-0.154^{\mathrm{a}}$ & -0.142 & 16.0 & 5.4 \\
\hline 15 & 0 & 226 & $0.700^{\mathrm{a}}$ & 0.629 & 0.0 & 72.5 & $-0.177^{\mathrm{a}}$ & -0.170 & 17.7 & 5.6 \\
\hline 18 & 0 & 223 & $0.675^{\mathrm{a}}$ & 0.594 & 0.0 & 64.0 & $-0.196^{\mathrm{a}}$ & -0.192 & 18.9 & 5.3 \\
\hline 21 & 0 & 220 & $0.644^{\mathrm{a}}$ & 0.555 & 0.2 & 55.2 & $-0.214^{\mathrm{a}}$ & -0.204 & 19.9 & 5.6 \\
\hline 24 & 0 & 217 & $0.606^{\mathrm{a}}$ & 0.499 & 0.9 & 45.7 & $-0.210^{\mathrm{a}}$ & -0.202 & 20.7 & 6.7 \\
\hline 36 & 0 & 205 & $0.584^{\mathrm{a}}$ & 0.447 & 2.4 & 38.1 & $-0.194^{\mathrm{a}}$ & -0.206 & 22.2 & 10.9 \\
\hline 48 & 0 & 193 & $0.637^{\mathrm{a}}$ & 0.465 & 3.6 & 43.3 & $-0.294^{\mathrm{a}}$ & -0.324 & 34.6 & 11.9 \\
\hline 60 & 0 & 181 & $0.692^{\mathrm{a}}$ & 0.566 & 3.4 & 51.2 & $-0.364^{\mathrm{a}}$ & -0.454 & 41.6 & 13.1 \\
\hline 1 & 1 & 60 & $0.803^{\mathrm{a}}$ & 0.726 & 0.0 & 98.0 & $-0.063^{\mathrm{a}}$ & -0.131 & 16.8 & 6.6 \\
\hline 1 & 2 & 60 & $0.778^{\mathrm{a}}$ & 0.760 & 0.0 & 88.5 & $-0.075^{\mathrm{a}}$ & -0.066 & 8.5 & 3.3 \\
\hline 1 & 3 & 60 & $0.818^{\mathrm{a}}$ & 0.827 & 0.0 & 96.5 & $-0.134^{\mathrm{a}}$ & -0.178 & 18.4 & 4.2 \\
\hline 1 & 4 & 60 & $0.512^{\mathrm{a}}$ & 0.418 & 0.5 & 48.9 & $0.048^{\mathrm{b}}$ & 0.010 & 8.1 & 5.6 \\
\hline 3 & 1 & 58 & $0.799^{\mathrm{a}}$ & 0.736 & 0.0 & 88.6 & $-0.069^{\mathrm{a}}$ & -0.122 & 9.5 & 6.0 \\
\hline 3 & 2 & 58 & $0.787^{\mathrm{a}}$ & 0.755 & 0.0 & 84.8 & $-0.123^{\mathrm{a}}$ & -0.132 & 13.4 & 5.3 \\
\hline 3 & 3 & 58 & $0.793^{\mathrm{a}}$ & 0.784 & 0.0 & 90.9 & $-0.052^{\mathrm{b}}$ & -0.119 & 15.5 & 6.5 \\
\hline 3 & 4 & 58 & $0.484^{\mathrm{a}}$ & 0.432 & 1.8 & 43.2 & 0.038 & -0.027 & 13.8 & 12.2 \\
\hline 6 & 1 & 55 & $0.759^{\mathrm{a}}$ & 0.720 & 0.1 & 76.6 & $-0.061^{\mathrm{b}}$ & -0.022 & 14.5 & 12.7 \\
\hline 6 & 2 & 55 & $0.809^{\mathrm{a}}$ & 0.741 & 0.0 & 83.7 & $-0.133^{\mathrm{a}}$ & -0.144 & 17.8 & 8.5 \\
\hline 6 & 3 & 55 & $0.800^{\mathrm{a}}$ & 0.768 & 0.0 & 82.6 & $-0.059^{\mathrm{b}}$ & -0.130 & 14.2 & 7.0 \\
\hline 6 & 4 & 55 & $0.478^{\mathrm{a}}$ & 0.412 & 3.5 & 34.1 & $0.067^{\mathrm{b}}$ & 0.045 & 13.7 & 13.5 \\
\hline 9 & 1 & 52 & $0.721^{\mathrm{a}}$ & 0.670 & 0.2 & 63.5 & -0.064 & 0.024 & 18.6 & 21.3 \\
\hline 9 & 2 & 52 & $0.800^{\mathrm{a}}$ & 0.690 & 0.7 & 80.8 & $-0.133^{\mathrm{a}}$ & -0.160 & 24.5 & 12.6 \\
\hline 9 & 3 & 52 & $0.812^{\mathrm{a}}$ & 0.761 & 0.2 & 77.9 & -0.048 & -0.074 & 14.0 & 9.5 \\
\hline 9 & 4 & 52 & $0.551^{\mathrm{a}}$ & 0.564 & 5.4 & 39.0 & 0.079 & 0.019 & 16.6 & 17.8 \\
\hline 12 & 1 & 49 & $0.700^{\mathrm{a}}$ & 0.651 & 0.9 & 64.1 & $-0.059^{c}$ & 0.036 & 19.2 & 23.7 \\
\hline 12 & 2 & 49 & $0.796^{\mathrm{a}}$ & 0.660 & 2.0 & 84.5 & $-0.150^{\mathrm{a}}$ & -0.226 & 37.6 & 18.2 \\
\hline 12 & 3 & 49 & $0.859^{\mathrm{a}}$ & 0.778 & 0.1 & 75.4 & $-0.102^{\mathrm{b}}$ & -0.106 & 15.5 & 13.0 \\
\hline 12 & 4 & 49 & $0.601^{\mathrm{a}}$ & 0.645 & 6.6 & 44.2 & -0.002 & -0.092 & 21.8 & 19.6 \\
\hline 15 & 1 & 46 & $0.649^{\mathrm{a}}$ & 0.582 & 0.9 & 62.9 & -0.042 & 0.087 & 17.8 & 24.3 \\
\hline 15 & 2 & 46 & $0.780^{\mathrm{a}}$ & 0.636 & 3.3 & 82.5 & $-0.164^{\mathrm{a}}$ & -0.257 & 48.0 & 22.5 \\
\hline 15 & 3 & 46 & $0.853^{\mathrm{a}}$ & 0.772 & 0.0 & 67.7 & $-0.087^{\mathrm{b}}$ & -0.148 & 17.3 & 13.8 \\
\hline 15 & 4 & 46 & $0.536^{\mathrm{a}}$ & 0.549 & 7.8 & 40.0 & 0.055 & -0.062 & 21.0 & 20.9 \\
\hline 18 & 1 & 43 & $0.627^{\mathrm{a}}$ & 0.590 & 2.3 & 56.9 & -0.038 & 0.067 & 17.3 & 21.9 \\
\hline 18 & 2 & 43 & $0.767^{\mathrm{a}}$ & 0.613 & 3.8 & 79.6 & $-0.170^{\mathrm{a}}$ & -0.265 & 49.7 & 25.3 \\
\hline 18 & 3 & 43 & $0.852^{\mathrm{a}}$ & 0.767 & 0.5 & 59.6 & $-0.121^{\mathrm{b}}$ & -0.295 & 24.4 & 16.4 \\
\hline 18 & 4 & 43 & $0.523^{\mathrm{a}}$ & 0.626 & 10.8 & 38.0 & 0.057 & -0.158 & 23.5 & 22.9 \\
\hline
\end{tabular}

Table notes: a, b, and c denote statistically significant at the $1 \%, 5 \%$, and $10 \%$ level, respectively, using a two-tailed $t$-test. 


\section{Table $\mathbf{X}$}

Regressions of Exchange Rate Exposure Estimates on Foreign-And-Export Sales and Size Residual Currency Exposure Estimates (CRSP Size-portfolio control)

Currency exposures are estimated using monthly overlapping observations over the period 7701-9612. We measure foreign-and-export sales (\%FGN Sales) and size (MVE) using, respectively, the mean annual foreign-and-export sales and mean market value of equity over the period 7701-9612.

\begin{tabular}{|c|c|c|c|c|}
\hline Horizon & Constant & $\%$ FGN Sales & MVE & Adj. $\mathrm{R}^{2}$ \\
\hline 01 & $\begin{array}{l}-0.042 \\
(-3.619) * * *\end{array}$ & $\begin{array}{l}-0.355 \\
(-5.204)^{* * *}\end{array}$ & $\begin{array}{l}-0.006 \\
(-3.421)^{* * *}\end{array}$ & 0.065 \\
\hline 03 & $\begin{array}{l}-0.047 \\
(-3.248) * * *\end{array}$ & $\begin{array}{l}-0.416 \\
(-4.928)^{* * *}\end{array}$ & $\begin{array}{l}-0.005 \\
(-1.970)^{* *}\end{array}$ & 0.045 \\
\hline 06 & $\begin{array}{l}-0.05 \\
(-2.958) * * *\end{array}$ & $\begin{array}{l}-0.579 \\
(-5.758) * * *\end{array}$ & $\begin{array}{l}-0.003 \\
(-1.275)\end{array}$ & 0.051 \\
\hline 09 & $\begin{array}{l}-0.066 \\
(-3.318)^{* * *}\end{array}$ & $\begin{array}{l}-0.667 \\
(-5.772)^{* * *}\end{array}$ & $\begin{array}{c}-0.002 \\
(-0.796)\end{array}$ & 0.048 \\
\hline 12 & $\begin{array}{l}-0.081 \\
(-3.741)^{* * *}\end{array}$ & $\begin{array}{l}-0.769 \\
(-6.068)^{* * *}\end{array}$ & $\begin{array}{c}-0.004 \\
(-1.126)\end{array}$ & 0.055 \\
\hline 15 & $\begin{array}{l}-0.097 \\
(-4.225)^{* * *}\end{array}$ & $\begin{array}{l}-0.816 \\
(-6.077)^{* * * *}\end{array}$ & $\begin{array}{l}-0.005 \\
(-1.498)\end{array}$ & 0.058 \\
\hline 18 & $\begin{array}{l}-0.109 \\
(-4.481)^{* * *}\end{array}$ & $\begin{array}{l}-0.873 \\
(-6.143) * * *\end{array}$ & $\begin{array}{c}-0.006 \\
(-1.563)\end{array}$ & 0.060 \\
\hline 21 & $\begin{array}{l}-0.117 \\
(-4.467) * * *\end{array}$ & $\begin{array}{l}-0.96 \\
(-6.279) * * *\end{array}$ & $\begin{array}{c}-0.007 \\
(-1.611)\end{array}$ & 0.063 \\
\hline 24 & $\begin{array}{l}-0.109 \\
(-3.936)^{* * *}\end{array}$ & $\begin{array}{l}-0.997 \\
(-6.181)^{* * *}\end{array}$ & $\begin{array}{c}-0.006 \\
(-1.377)\end{array}$ & 0.059 \\
\hline 36 & $\begin{array}{l}-0.091 \\
(-2.792) * * *\end{array}$ & $\begin{array}{l}-1.082 \\
(-5.669) * * *\end{array}$ & $\begin{array}{c}-0.001 \\
(-0.156)\end{array}$ & 0.042 \\
\hline 48 & $\begin{array}{l}-0.183 \\
(-4.844)^{* * *}\end{array}$ & $\begin{array}{l}-1.055 \\
(-4.793)^{* * *}\end{array}$ & $\begin{array}{c}-0.005 \\
(-0.897)\end{array}$ & 0.034 \\
\hline 60 & $\begin{array}{l}-0.237 \\
(-5.723)^{* * *}\end{array}$ & $\begin{array}{l}-0.973 \\
(-4.016)^{* * *}\end{array}$ & $\begin{array}{c}-0.013 \\
(-1.934) *\end{array}$ & 0.032 \\
\hline
\end{tabular}

$*$, **, and $* * *$ denote statistically significant at the $1 \%, 5 \%$, and $10 \%$ level, respectively, using a two-tailed $t$-test. 
Figure 1

US Dollar Trade-Weighted Real Index (March 1973=100)

The real currency index is calculated by subtracting a self-constructed trade-weighted inflation index of the G10 countries from the Federal Reserve's (1978) US Dollar trade-weighted nominal index. By construction, an increase in the currency index corresponds to an appreciation of the US Dollar in real term.

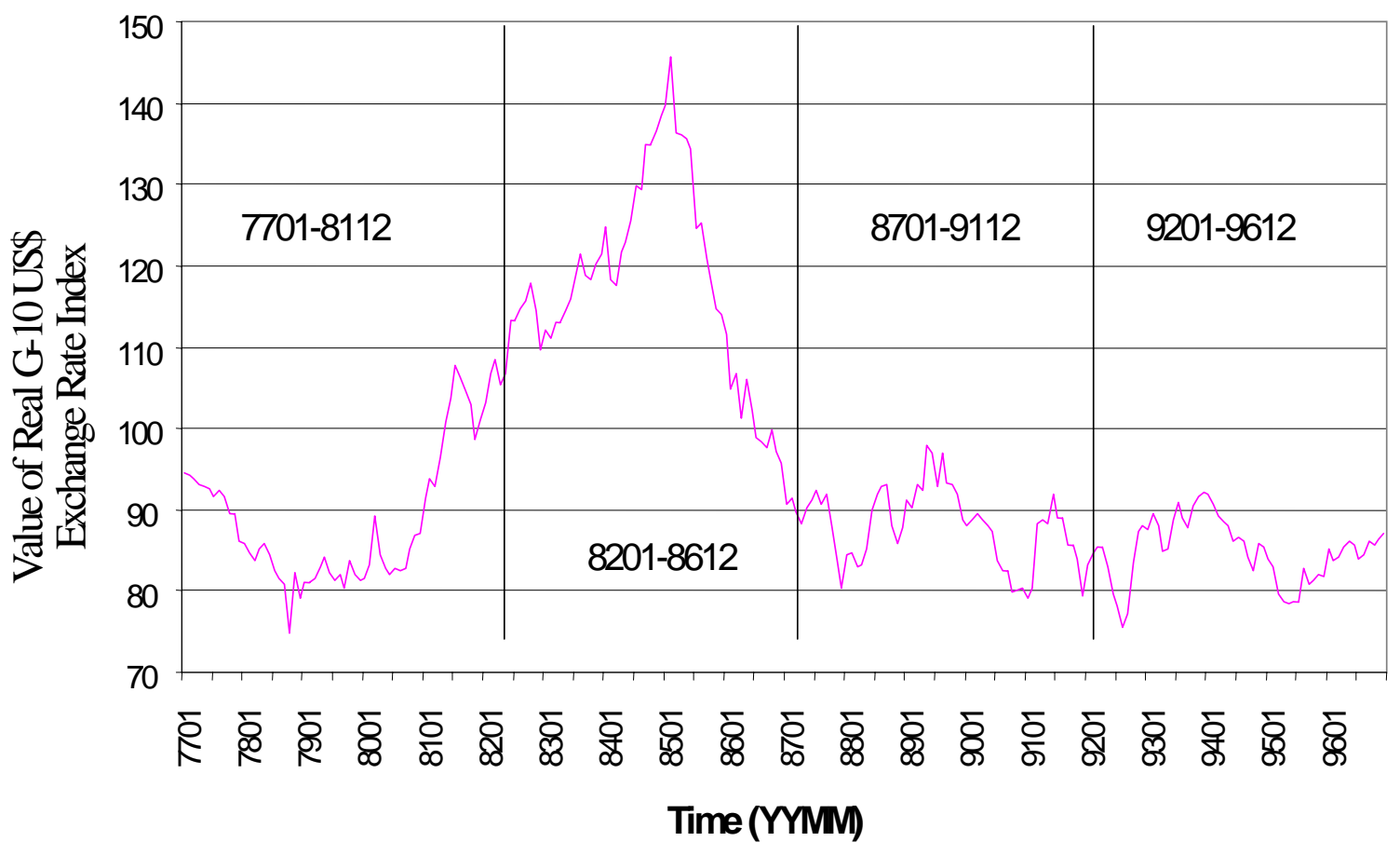


Figure 2

Distribution of Equity Return Total Exchange Rate Exposure Estimates Not Control for Market Wide Effect

Full Period 7701 - 9612

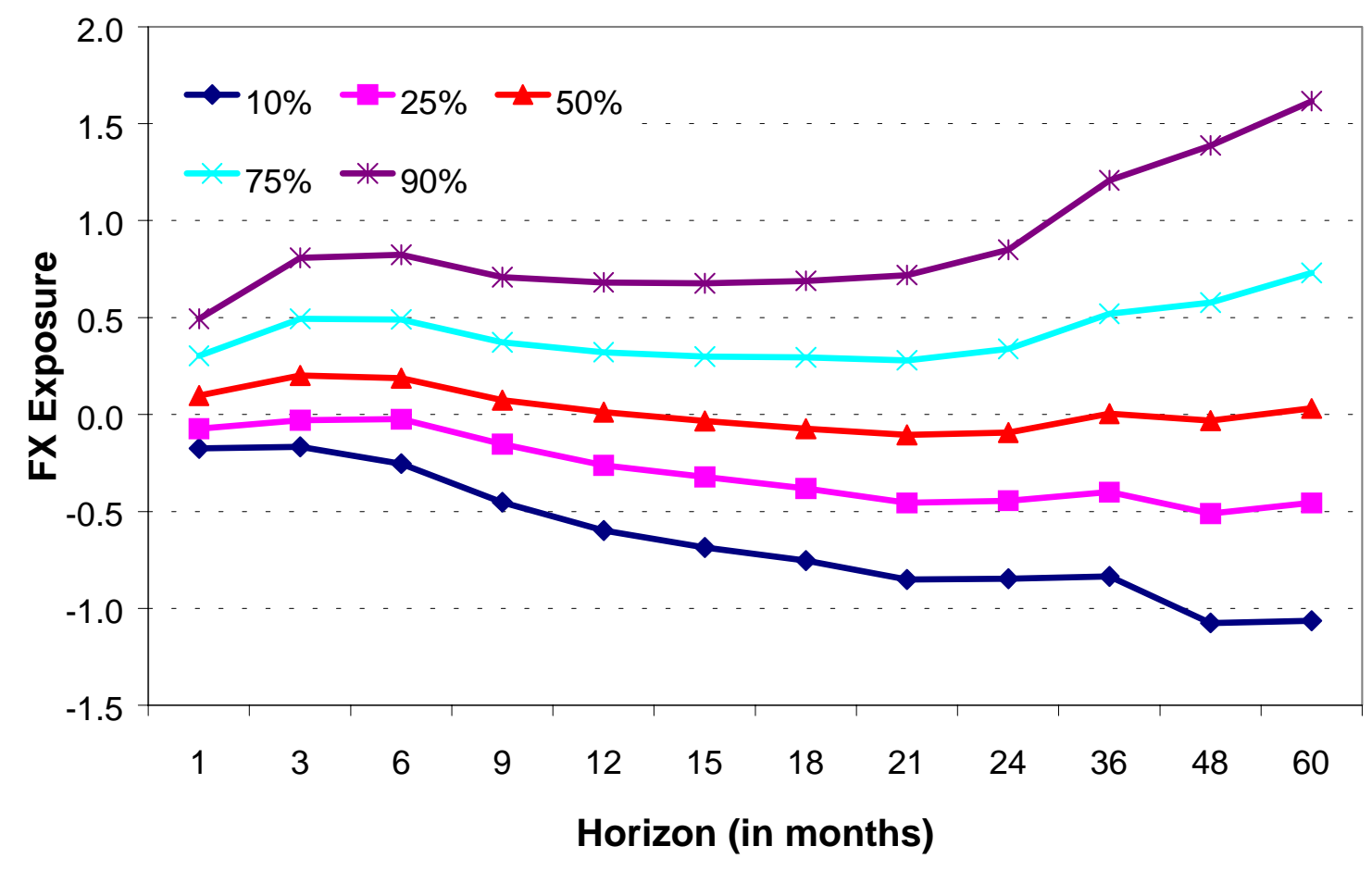

Subperiods

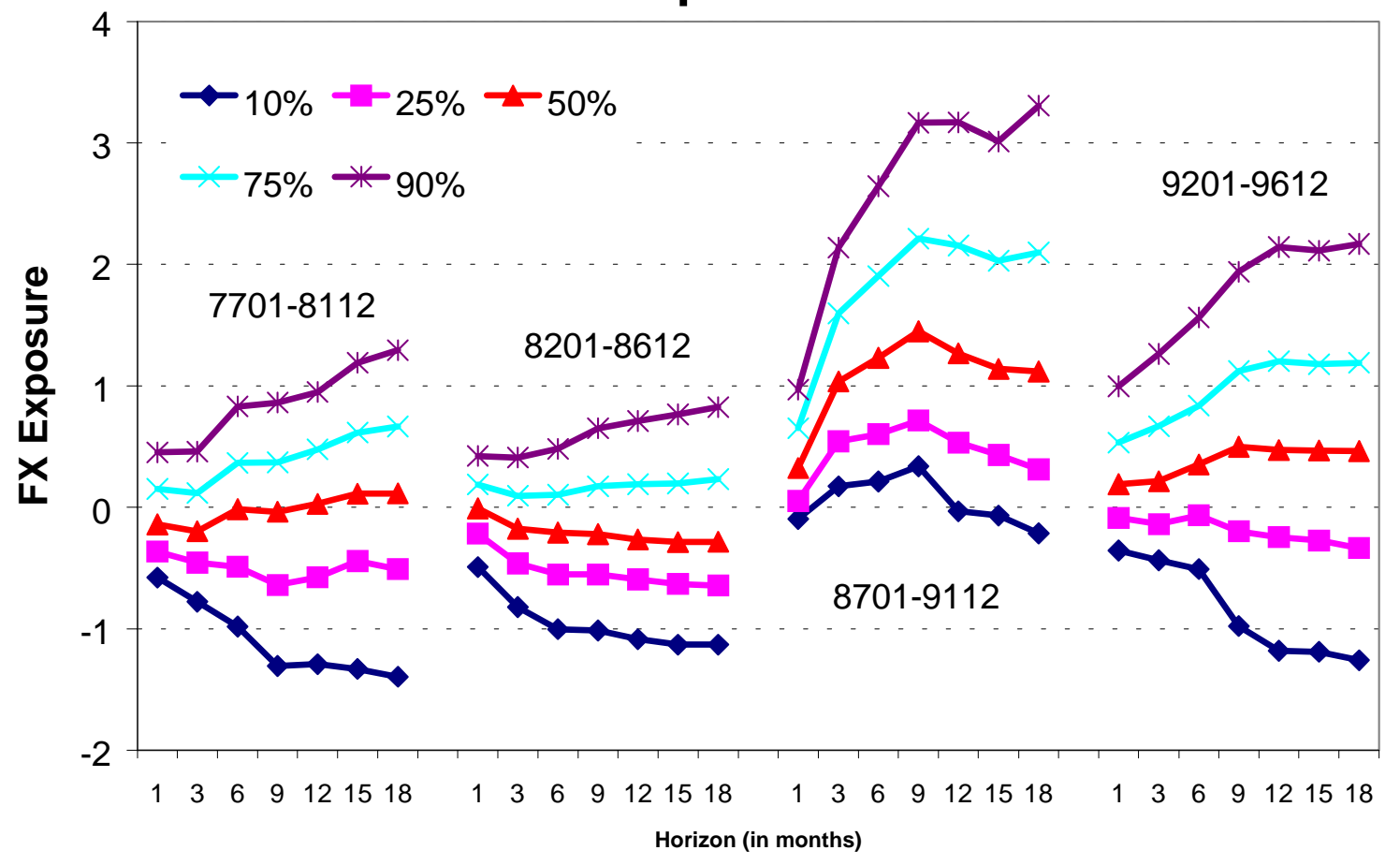


Figure 3

Distribution of Equity Return Exchange Rate Exposure Estimates Controlled for Value-weighted market.

Full Period 7701-9612

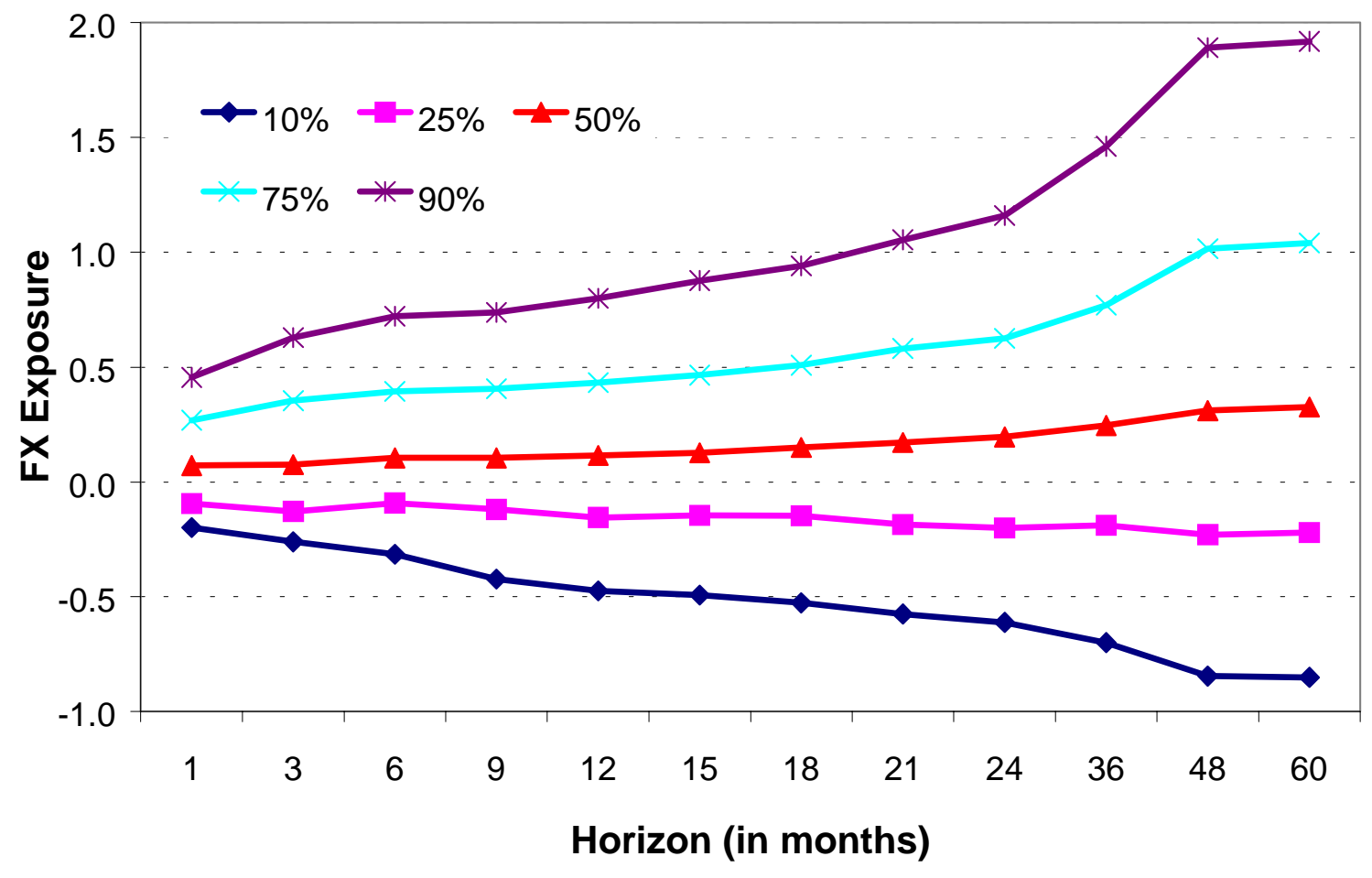

Subperiods

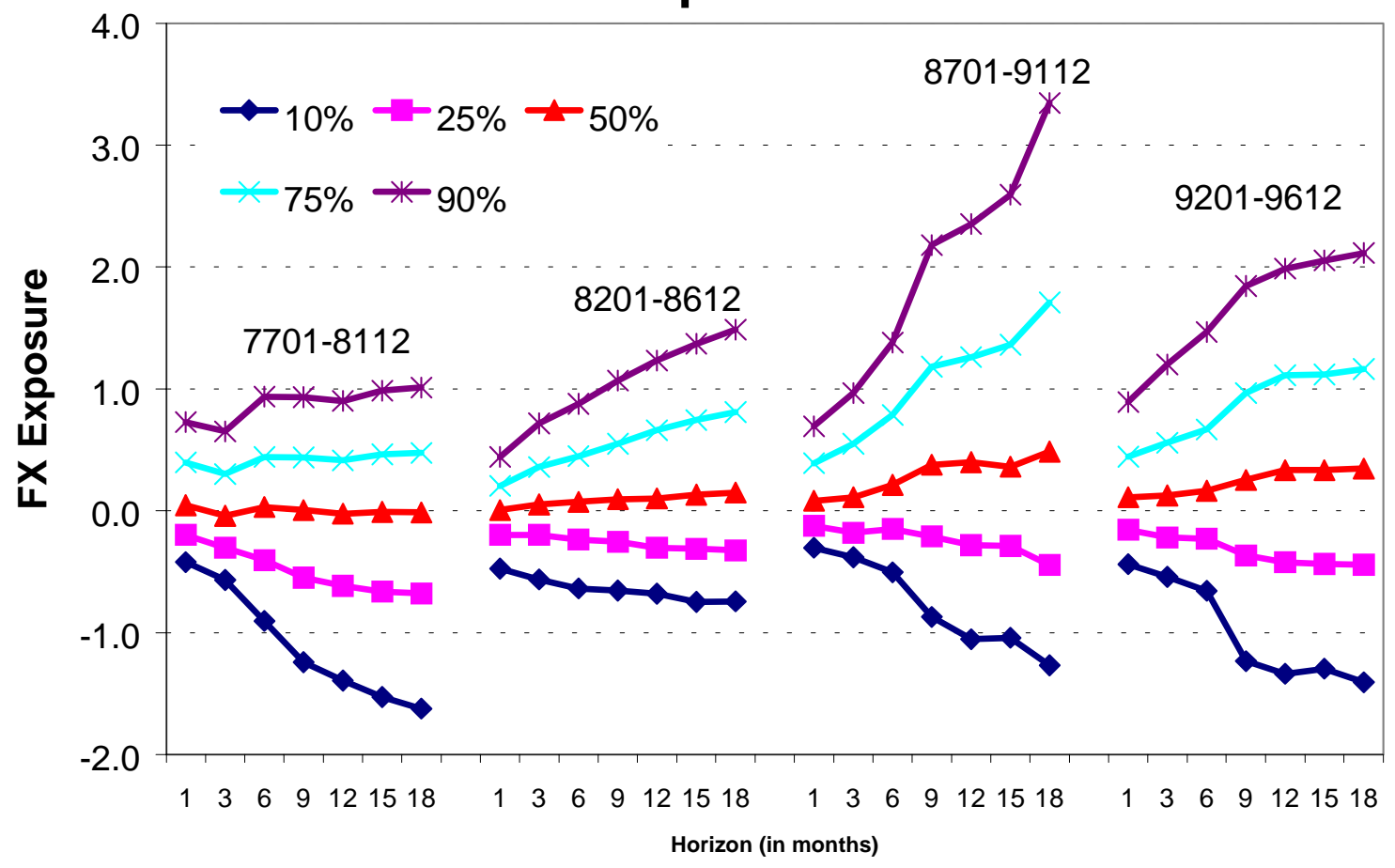


Figure 4

Distribution of Equity Return Exchange Rate Exposure Estimates Controlled for Equal-weighted market

\section{Full Period 7701- 9612}

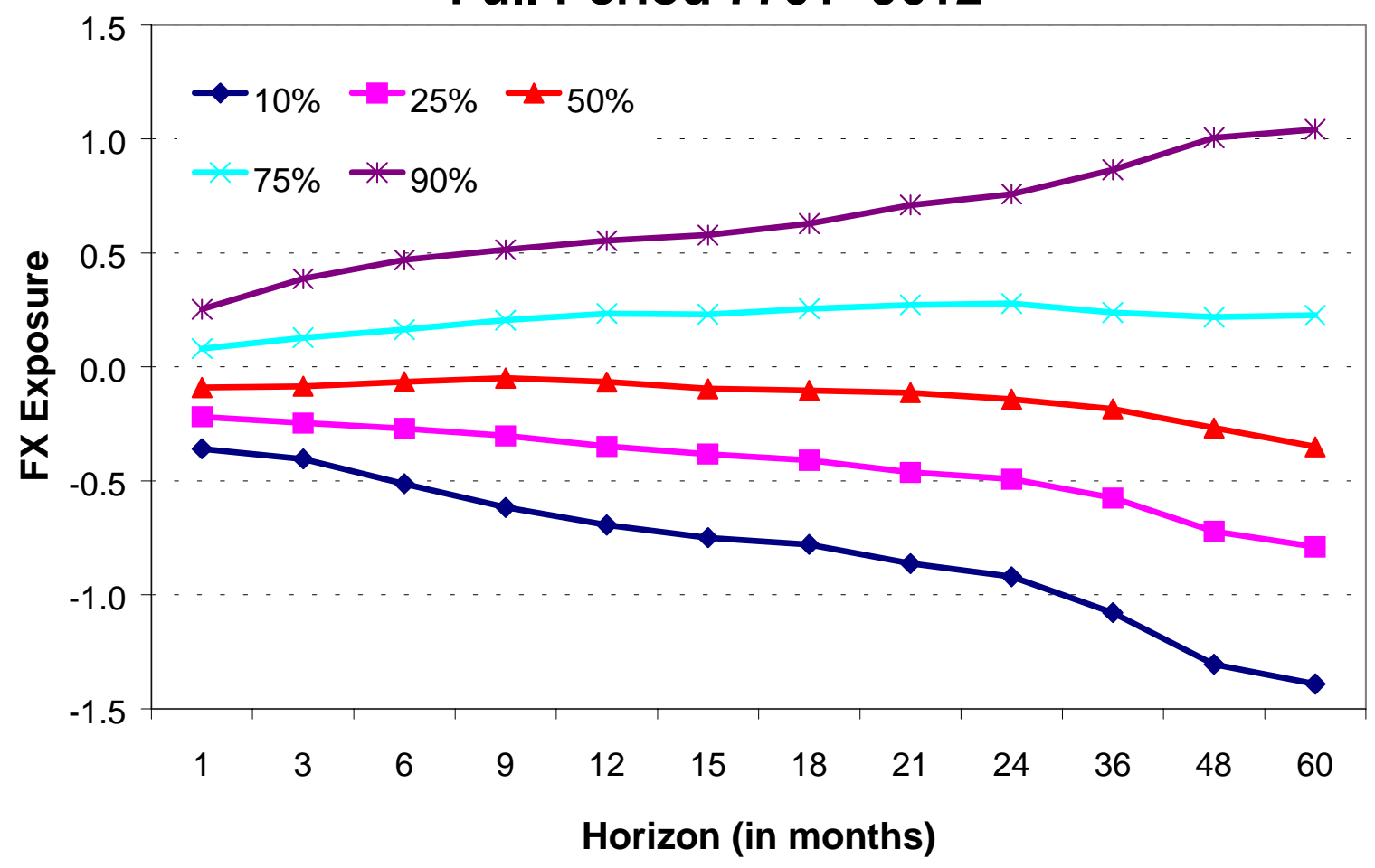

Subperiods

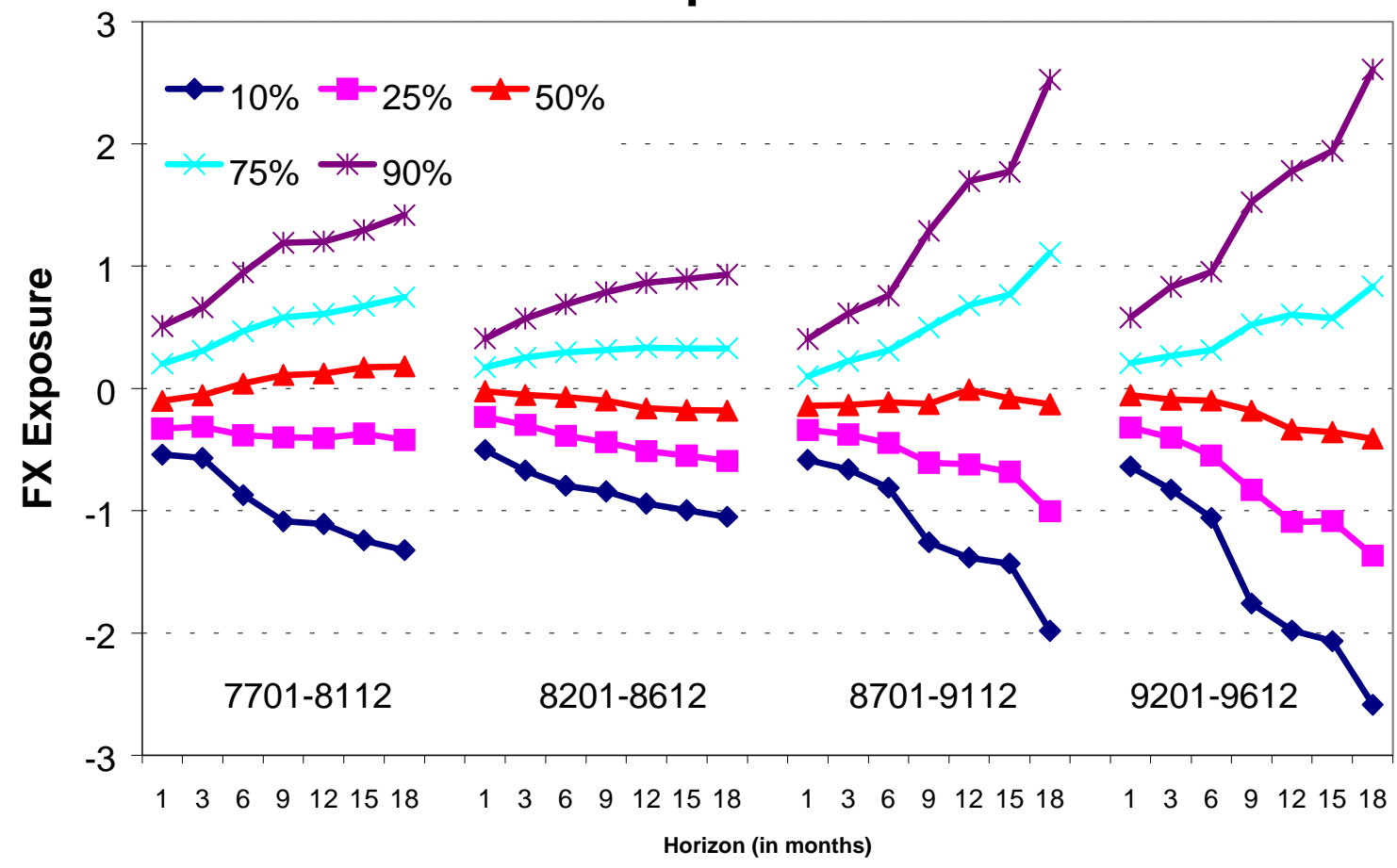


Figure 5

Equity Market Exchange Rate Exposure Estimates

Five-year Rolling Window Estimation
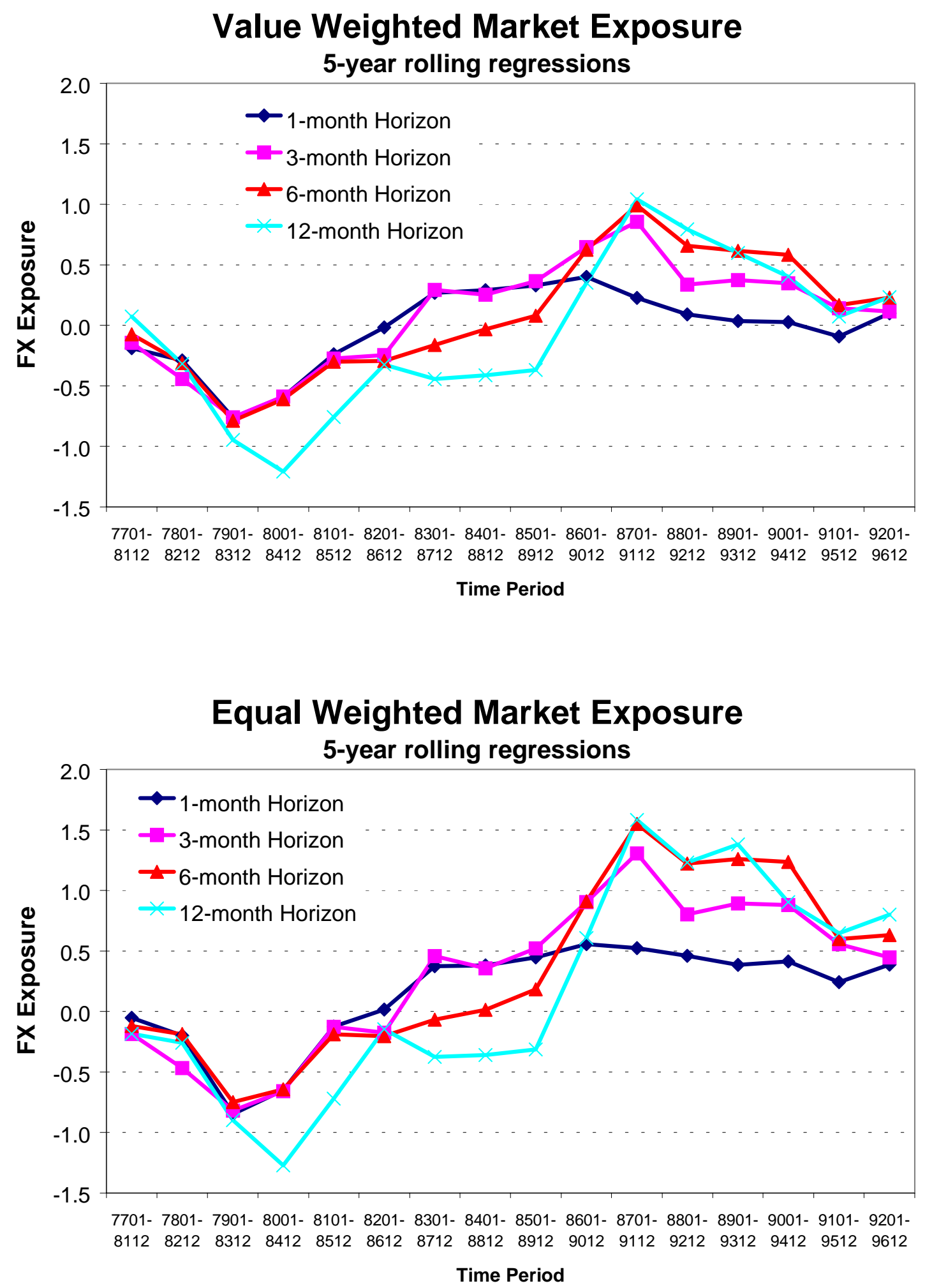
Figure 6

CRSP Cap-Based Portfolio Exchange Rate Exposure Estimates

Size 1 (10) is the Largest (Smallest) Portfolio

Full Period 7701 - 9612
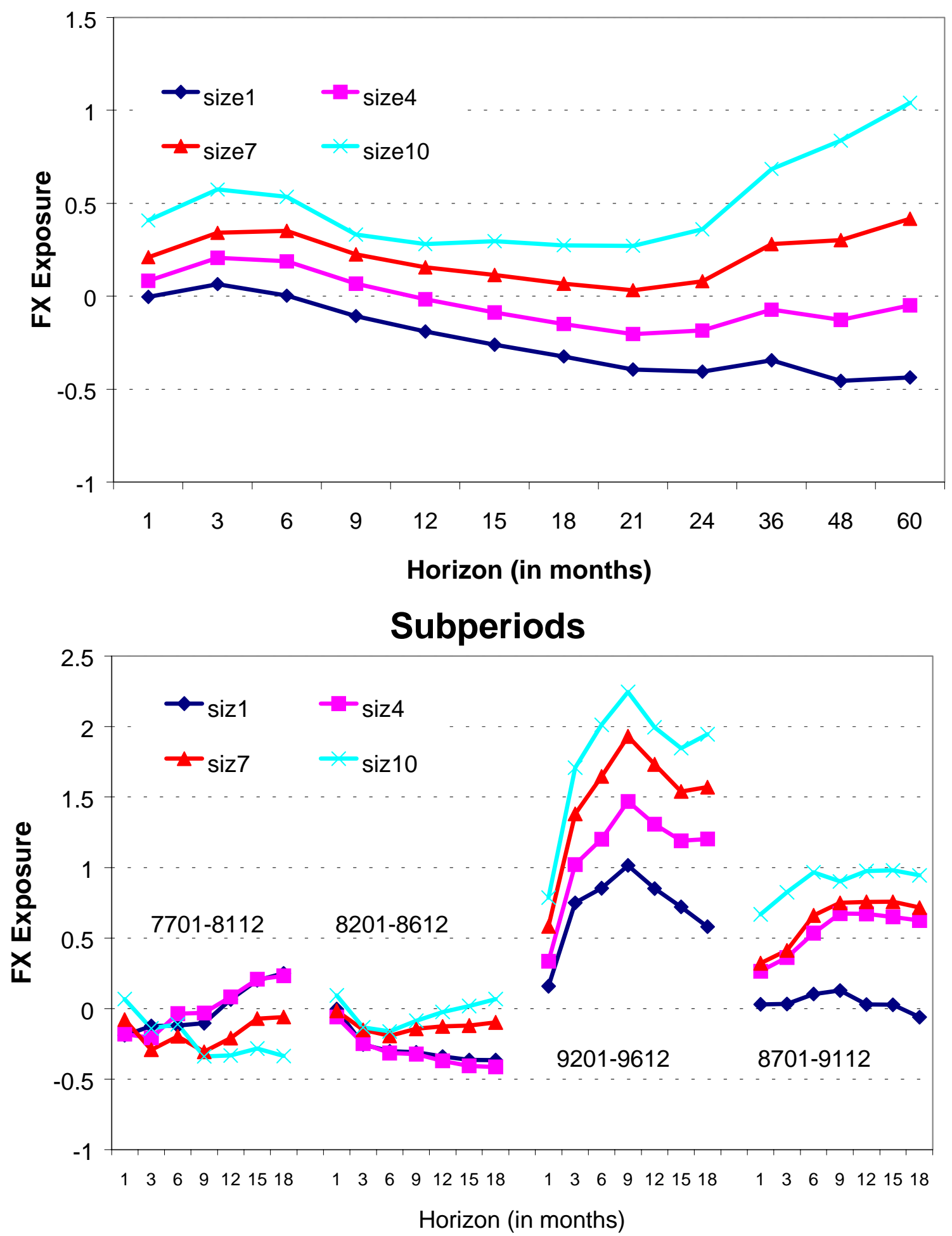
Figure 7

Exchange Rate Exposure of Four Selected Size Portfolios

The portfolios are constructed by first dividing firms into ten deciles according to their market capitalization in the beginning of the year. For each sample year and size decile, we further divided the firms into three sub-portfolios: high, low, and zero foreign-and-export sales. We compute foreign-and-export sales as the sum of foreign sales and export sales, scaled by total firm sales.

\section{High Foreign Sales}

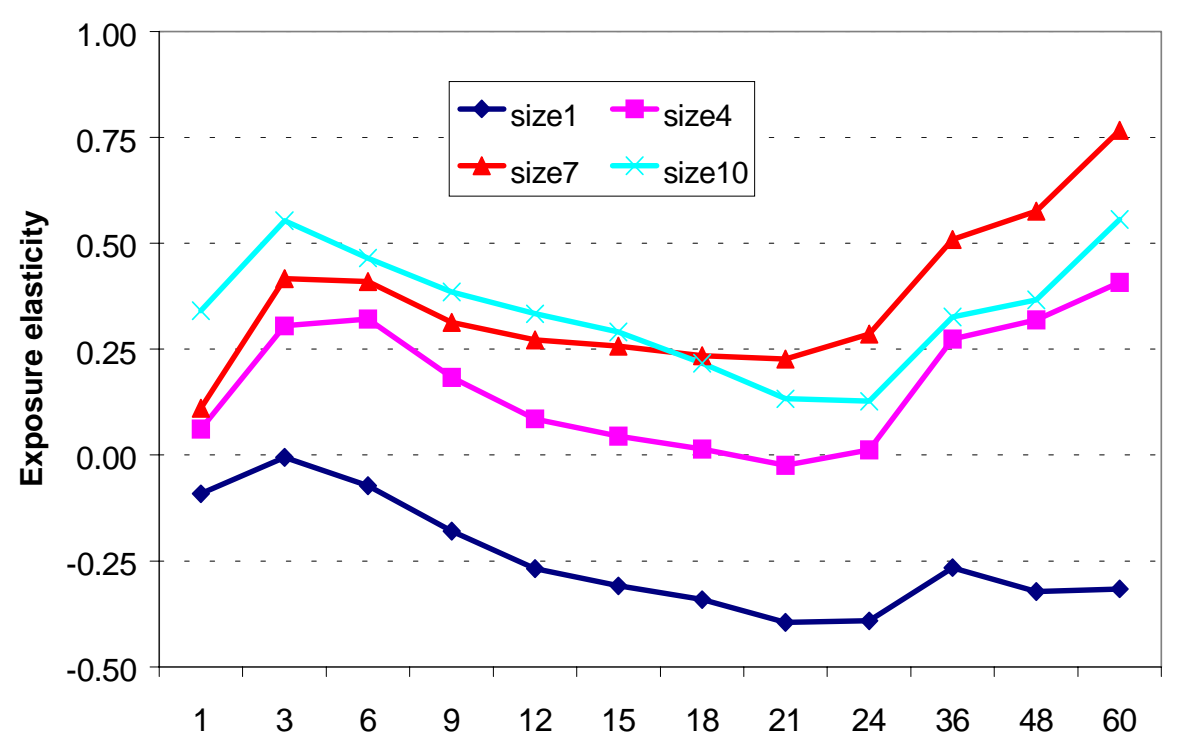

\section{Low Foreign Sales}

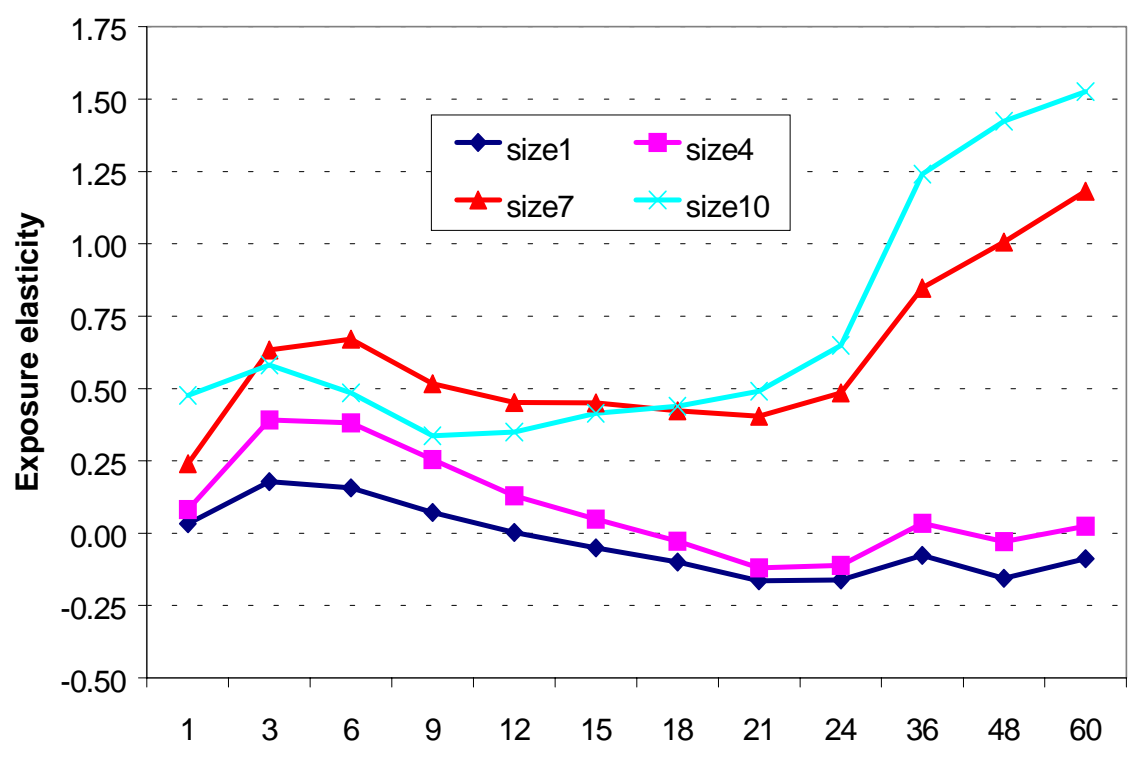

\section{Zero Foreign Sales}

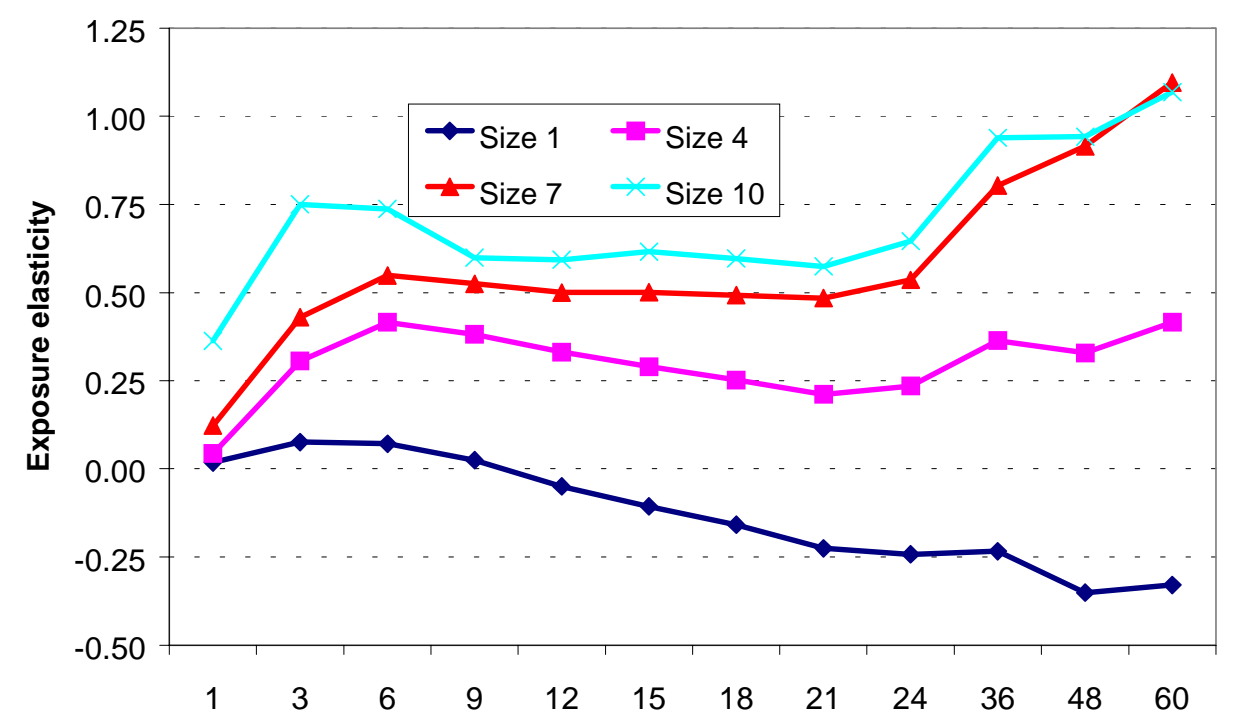

